\title{
A REVIEW OF RECENT RESEARCH ON NUTRITION AND METABOLISM IN THE ATHLETIC HORSE
}

\author{
K. M. HINEY AND G. D. POTTER
}

Equine Sciences Program, Department of Animal Science, Texas A \& M University College Station, TX, 77845 USA

\section{CONTENTS}

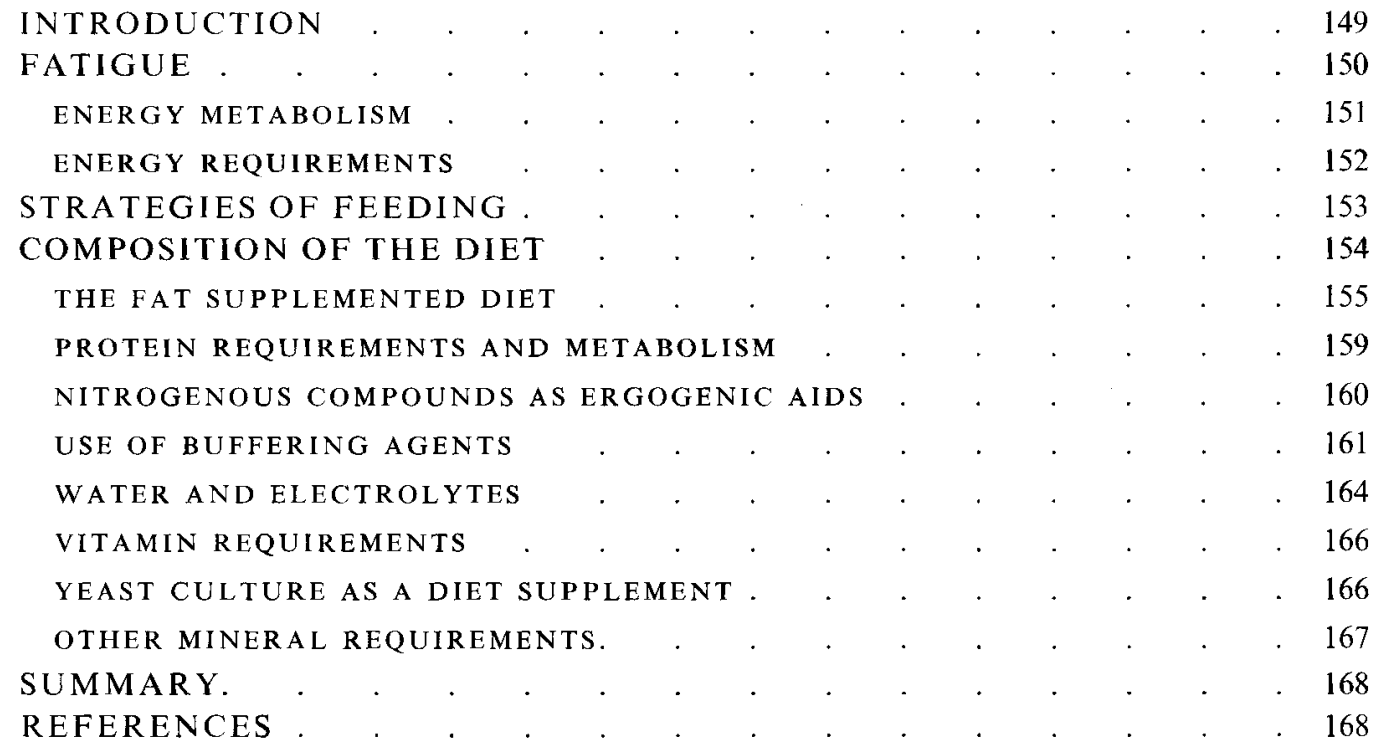

\section{INTRODUCTION}

This review is directed toward research on nutrition, metabolism and related subjects pertaining to the racehorse and other equine athletes. The authors have attempted to review all relevant research published in the last 5 years, and we apologize for any omissions of published work that may have occurred - it was not by intent.

For purposes of presentation, this review is organized into sections of related information, i.e. energy metabolism (with subsections on muscle glycogen utilization, utilization of fat supplemented diets, strategies of feeding, use of sodium bicarbonate as a buffer against anaerobic acidosis), protein metabolism (with subsections on nitrogenous compounds as ergogenic aids), vitamins and electrolytes (with discussion of water balance). As will be evident in this review, most of the work reported in the last 5 years has focused on energy metabolism and related subjects. This is logical as exercise changes energy requirements of horses more than requirements for other nutrients.

In order to evaluate the effect of dietary manipulation on performance parameters, standard tests have been established which may or may not be unique to equine research. Fitness of a horse is typically measured by cardiopulmonary standards. $V_{200}$, the velocity 
at which a horse achieves a heart rate of $200 \mathrm{bpm}$, and $\mathrm{V}_{\mathrm{La}}$, the velocity at which lactate concentration reaches $4 \mathrm{mmol} / \mathrm{l}$, are used to monitor the increasing efficiency of the cardiovascular system. These values should increase as the animal becomes more fit. Other standard measures of performance are $\dot{V}_{\mathrm{O}_{2, \text { max }}}$ which is indicative of the velocity at which $\mathrm{O}_{2}$ uptake is maximal. In addition, run time to fatigue, or the total time a horse can be made to exercise using humane methods, is a commonly used measure in equine studies. Other tests used to determine the efficacy of certain nutritional practices include monitoring changes in glycogen stores in the muscle by taking biopsies and determining glycogen concentrations. Standard exercise tests are then developed by each individual researcher which vary according to the parameter to be tested. These may be performed on a treadmill, under saddle on a track, following a mechanical cow, pulling weight sleds etc.

\section{FATIGUE}

The primary concern of most researchers that focus on the equine athlete is to improve athletic performance or reduce injury to the horse. Trainers in the racing industry are constantly searching for means to decrease race times, improve the competitiveness of the individual animal and prolong the productive career of the animal. The traditional method to achieve these aims has been selective breeding. This is a lengthy process with sometimes unpredictable results. However, the performance of the equine athlete may be directly alterable by manipulation of feeding, training, and management regimens. Much knowledge has been gained in the last 20 years regarding the physiology and nutritional needs of racehorses. Much more work is needed to determine the optimal nutritional programme to achieve maximal power output, stamina, and overall performance of the equine.

It is fairly obvious that feeding a horse different diets does not increase the inherent genetic capability of the animal for speed. It is apparent, however, that horses frequently encounter acute fatigue during racing or other performances. What researchers hope to achieve through diet and training manipulation is a delay in reaching fatigue. Indeed, this may be the most significant way to enhance performance at this time. Most horses in racing situations enter a state of fatigue as exhibited by a decrease in speed in the later stages of the race. The exact cause of fatigue has not been defined but various factors are believed to contribute to it. In the horse, these include low blood glucose, depletion of muscle glycogen, metabolic acidosis, lactate and $\mathrm{NH}_{3}$ accumulation, and loss of muscle ATP.

During strenuous exercise when $\mathrm{O}_{2}$ can be limiting, Type II muscle fibres are recruited for generation of power. The Type II b fibres are the fast twitch, glycolitic fibres responsible for high speed and high power contraction (Powers \& Howley, 1994). The primary fuel used in these conditions is therefore muscle glycogen. A direct relationship exists between the intensity of the exercise bout and the amount of glycogen used for energy. Depletion of muscle glycogen may result in fatigue or decreased performance, but it does appear that glycogen stores cannot be reduced to zero during canter performances. Horses exercised to fatigue still had 400-500 $\mathrm{mmol}$ glycogen $/ \mathrm{kg}$ freeze-dried muscle tissue (Essén-Gustavsson et al. 1991).

Histochemical analysis showed that almost all Type I fibres were depleted of glycogen and Type IIa fibres showed a reduction in glycogen. Type I and IIa fibres are the slow and fast twitch oxidative fibres, respectively, that are used predominantly in submaximal extended exercise. This study seems to indicate that glycogenolysis contributed to energy production even during submaximal exercise. Therefore, fatigue may not be due to overall glycogen depletion in the muscle, but rather to depletion in the individual types of muscle fibres. 
Another reason why a horse reaches fatigue or decreases its performance level during the latter stages of intense exercise appears to be the development of systemic or muscular acidosis. The end product of glycogen breakdown in anaerobic conditions is lactic acid, which dissociates into lactate and hydrogen ions. The reduction in $\mathrm{pH}$ due to the rising concentration of $\mathrm{H}^{+}$can impair muscular contraction by decreasing enzyme activity and contractability of the muscle (Powers \& Howley, 1994). Harris et al. (1991) observed a decrease in speed with increasing pre-exercise muscular acidosis between consecutive $700 \mathrm{~m}$ runs in three of four maximally exercised Thoroughbreds. However, no association between gallop times of successive runs and the rate of plasma ammonia $\left(\mathrm{NH}_{3}\right)$ accumulation relative to lactate, indicators of adenine nucleotide loss and muscular acidosis, was found (Harris et al. 1991). Powell et al. (1991) found a significant positive correlation between muscle $\mathrm{pH}$, lactate concentrations and fatigue time. Interestingly, horses with the longest time to fatigue had the highest lactate concentrations and lowest muscle $\mathrm{pH}$.

Increases in blood lactate concentrations may reflect a number of events, such as low muscle oxygen, accelerated glycolysis or reduced rate of lactate removal. Increased lactate concentrations occur when production exceeds removal. Lactate continues to accumulate after the cessation of exercise (Harris et al. 1991). Lactate is cleared from the blood by storage (redistribution), oxidation or gluconeogenesis. Lactic acid is not only a toxic waste product, as lactate may be used as an oxidizable substrate by cardiac and skeletal muscle or converted back to glycogen after work ceases. The observation that highly trained athletes have lower lactate accumulation may be owing to an increased rate of utilization and not decreased production (Powers \& Howley, 1994). Birks et al. (1991) also found that exercise itself increases the rate of lactate clearance.

Deamination of adenine nucleotides to inosine monophosphate occurs with sustained high intensity exercise such as racing and results in increased plasma $\mathrm{NH}_{3}$ (Beaunoyer et al. 1991). Ammonia may hasten fatigue by inhibiting pyruvate carboxylase and isocitrate dehydrogenase and consequently causing the accumulation of pyruvate. Ammonia may also decrease the entry of $\alpha$-ketoglutarate into the tricarboxylic acid (TCA) cycle by increasing glutamate formation, further increasing the buildup of pyruvate. Pyruvate will then be converted to lactate in oxygen limited conditions or when the TCA cycle is overwhelmed during rapid glycogenolysis, resulting in a decrease in muscle $\mathrm{pH}$.

Although various factors have been suggested as causes of fatigue in the horse, the exact aetiology of fatigue is not precisely known. Most likely it is a combination of these that results in the 'tired' horse, with some horses perhaps being more susceptible to changes in these parameters than others.

\section{ENERGY METABOLISM}

The primary substrates for energy production in the exercising horse are carbohydrates (CHO) and fats and, to a much lesser degree, protein. Protein catabolism is believed to account for no more than $5-15 \%$ of the energy provided during exercise, but the contribution may become greater if CHO stores become depleted (Lawrence, 1994). At rest, oxidation of fat is thought to supply most of the needs for energy; however, investigation of nutrient utilization using the arteriovenous differences of metabolites in the hind limb showed that glucose was a major fuel source, whether provided directly from the diet or synthesized via gluconeogenesis (Pethick et al. 1993).

As the horse exercises, energy requirements increase as a direct result of the need for ATP to facilitate contraction of the muscles. Based on established biochemical pathways and metabolism of the working muscle, the following is a suggested scenario for the exercising 
horse. At the initiation of exercise, a mixture of fat and $\mathrm{CHO}$ sources is oxidized to supply the increased demand for ATP. As the duration of submaximal exercise lengthens, the proportion of fatty acid (FA) oxidation supplying ATP increases while the percentage of $\mathrm{CHO}$ oxidation decreases (Costill, 1972). Horses exercised at $50 \% \dot{V}_{\mathrm{o}_{2} \max }$ for $75 \mathrm{~min}$ had a decreased respiratory quotient (RQ) value as exercise progressed, reflecting the shift to greater fat utilization (Rose et al. 1991). Exercise or stress results in the release of catecholamines, such as noradrenalin and adrenalin. These catecholamines quickly activate the enzyme triacylglycerol lipase $(E C$ 3.1.1.3) via a phosphorylation reaction. The activated enzyme increases the mobilization of fat and releases non-esterified fatty acids (NEFA) into the blood. These events are reflected by rising plasma NEFA concentrations owing to the increased rate of lipolysis. Despite the greater reliance on fat for fuel, carbohydrates (mainly blood glucose and glycogen) are still utilized during exercise. Duration of prolonged exercise on a treadmill was extended with i.v. infusions of a glucose polymer (Farris et al. 1995). While this is not suggested as a practical measure of improving performance during a contest, this study does indicate that $\mathrm{CHO}$ availability, especially blood glucose, may be a limiting factor in endurance performance.

As intensity of exercise increases and oxygen supply becomes more limited, there is a shift to a greater reliance on glycolytic catabolism of $\mathrm{CHO}$, mainly muscle glycogen. Gallops of 1000 and $1600 \mathrm{~m}$ resulted in a $25 \%$ decrease in muscle glycogen (Snow \& Harris, 1991). In a recent study examining maximal accumulated $\mathrm{O}_{2}$ deficit in Thoroughbreds and Standardbreds, anaerobic energy sources were calculated to supply $30 \%$ of the total energy during high intensity exercise (Eaton et al. 1995a). Extended submaximal exercise will also result in substantial depletion of muscle glycogen although the rate of utilization may be much lower. Horses completing 80 or $160 \mathrm{~km}$ endurance rides showed a decrease of 50-75\% in muscle glycogen (Snow \& Baxter, 1981; Snow et al. 1982; cited in Lawrence, 1994). As long as the intensity of exercise does not exceed oxygen availability, pyruvate metabolism should be adequate to prevent lactate accumulation.

\section{ENERGY REQUIREMENTS}

In the exercising horse dietary energy requirements change more than other nutrients. The conversion of stored energy to a form which yields movement is rather inefficient, with $80 \%$ of the energy being lost as heat in the horse (Hodgson et al. 1994). The National Research Council (1989) recommends that digestible energy requirements exceed maintenance by 25 , 50 and $100 \%$ for light, medium and intense work respectively. When horses were exercised for $75 \mathrm{~min}$ at $50 \% \dot{V}_{\mathrm{O}_{2 \max }}$, there was an increase in digestible energy (DE) requirements of $112 \%$ over maintenance, translating to a total requirement of $148.9 \mathrm{MJ} \mathrm{DE}$ (Rose et al. 1991). Energy requirements may also be altered by factors other than increased exercise. Administration of furosemide, a common practice in Thoroughbreds, may alter the work load by inducing weight loss and thus increasing the energetic response to exertion (Hinchcliff et al. 1993a). Body condition also affects energy needs. Horses with a moderately fat body condition score of 7.5 (Henneke et al. 1983 ) required $11.3 \mathrm{kcal} / \mathrm{kg}$ more DE daily for maintenance than horses in moderate condition (Webb et al. 1990). Environmental temperature may also affect energy requirements. Within the thermoneutral zone (TNZ), an animal can regulate its body temperature without altering metabolic rate by changing its behaviour or peripheral blood flow. Below the lower critical temperature (LCT), the lower limit of the TNZ, total heat loss will exceed thermoneutral heat production. Thus an animal will need extra feed to increase its heat production to maintain body temperature (Morgan, 1995). Morgan (1995) estimated that horses acclimatized to indoor conditions of $15-20^{\circ} \mathrm{C}$ had a LCT of $18.2^{\circ} \mathrm{C}$. At temperatures below the LCT the 
extra energy requirement can be met by supplying an additional $0.15 \mathrm{~kg}$ hay $/{ }^{\circ} \mathrm{C}$ below LCT. At temperatures above the TNZ, animals must again increase their metabolic rate in order to dissipate heat. Horses with a mean body condition score of 7.5 required more energy for maintenance during the hot season as compared with the temperate season (Webb et al. 1990). In addition, horses in fleshy condition may be less fit, as Lawrence et al. (1992) found that the most successful endurance horses in the 1990 Race of Champions had lower body condition scores than poor performers. Animals with a more moderate body condition score may be able to devote less of their energy production to temperature regulation and more to the task required of them. Therefore when formulating diets and feeding horses it is important to consider these additional factors such as amount and intensity of work, ambient temperature and body condition score in calculating energy requirements.

\section{STRATEGIES OF FEEDING}

Manipulation of the amount and type of feed, and time of ingestion of a meal before exercising, may alter performance. Ingestion of feed resulted in an increase in blood glucose $\sim 2 \mathrm{~h}$ after eating (Stull \& Rodiek, 1995 a, b), being dependent on the amount of readily absorbed $\mathrm{CHO}$ in the diet. The body responds to an observed rise in glucose concentrations by releasing insulin, which facilitates glucose uptake by the cells. It is commonly accepted that insulin decreases the rate of lipolysis and causes greater esterification and storage of NEFA. Therefore, if release of insulin results in lowered blood glucose or NEFA concentrations during exercise, performance may be diminished. Sticker et al. (1995) kept horses fasting for $73 \mathrm{~h}$ prior to exercise and observed an increase in blood glucose concentrations during exercise while glucose concentrations dropped in fed horses. Horses that fasted overnight were able to maintain steadier plasma glucose concentrations during exercise in comparison to horses given a meal of corn 2.5 to $3 \mathrm{~h}$ before exercise (Lawrence et al. 1993). Fed horses experienced a drop in blood glucose concentrations. Plasma NEFA concentrations were also higher in the horses that fasted. In an additional study by Lawrence et al. (1995) similar effects of feeding prior to exercise were observed, as well as lower glycogen utilization in the animals that fasted. These animals were probably able to use the greater amounts of FFA and glucose in the blood as alternatives to glycogen.

In addition to feeding practices prior to exercise, attention has been given to providing energy during the recovery period. It was speculated that increasing available substrates after exercise would hasten glycogen resynthesis (Davie et al. 1995). Glucose infusions of $3 \mathrm{~g} / \mathrm{kg}$ were administered to horses $30 \mathrm{~min}$ after exercise; although this increased blood glucose and insulin concentrations, there was no effect on glycogen resynthesis (Davie et al. 1994). However, when the infusion was increased to $6 \mathrm{~g} / \mathrm{kg}$, the rate of glycogen resynthesis during the first $12 \mathrm{~h}$ after exercise was 5-fold faster than that in animals fed a typical meal (Davie et al. 1995). Horses receiving a meal of $2 \mathrm{~kg}$ oats 1 or $4 \mathrm{~h}$ after exercise had a faster rate of glucose clearance than non-exercised horse (Brewster-Barnes et al. 1995). This is probably because the exercising muscle is more able to take up glucose after exercise. The study also showed that glycogenolysis continues after cessation of exercise. Feeding a CHO rich meal $1.5 \mathrm{~h}$ after an exercise bout may prevent further glycogen depletion. These observations may have implications for horses competing over successive days. Thus trainers should consider the time of the event in relation to the feeding schedule, whether before or after exercise. 


\section{COMPOSITION OF THE DIET}

The type of meal fed apparently alters the glycaemic response during exercise. Corn is a readily digested, high starch feedstuff while lucerne is relatively low in starch and much higher in insoluble carbohydrates. When meals of corn or lucerne were fed prior to exercise, there was a higher peak of blood glucose concentration after eating corn owing to the higher intake of soluble CHO (Stull \& Rodiek, 1995 $a, b$ ). During an exercise test, horses given corn experienced a decrease in blood glucose concentration, while in animals that fasted or were given lucerne, glucose concentrations rose gradually during the exercise test. This was interpreted by the authors to indicate greater utilization of glucose for energy in the animals given corn, as the greater insulin response may have aided in uptake of glucose by the working muscles. However, in a similar study by Rodiek et al. (1991) the decline in blood glucose concentration during exercise after a corn meal was assumed to be due to a lack of glucose available for work.

The type of feed may also alter catecholamine response. A meal of lucerne following a $24 \mathrm{~h}$ fast resulted in higher noradrenalin concentrations at rest and during exercise than did a meal of corn (Gabbard et al. 1995). Stimulation of the sympathetic nervous system with a low CHO diet increases lipolysis and NEFA concentrations in the blood, which the authors suggest may therefore spare glycogen stores and increase time to fatigue. NEFA concentrations at the initiation of and during exercise were also lower in the horses given corn when compared to those that fasted (Rodiek et al. 1991). At rest NEFA concentrations were not different in lucerne $v$. corn fed horses but the NEFA concentrations were found to be higher during exercise in the lucerne fed horses (Zimmerman et al. 1992).

Animals on a CHO-rich diet had higher concentrations of plasma NEFA at the beginning of exercise when compared to an isocaloric 'normal' diet of oats and barley. The horses on the CHO-rich diet also had higher resting muscle glycogen than horses on the normal diet and a fat-rich diet (Essén-Gustavsson et al. 1991). Glucose uptake was less when horses were fed these diets than when fed the normal diets. The animals on the CHOand fat-rich diets had a greater amount of glucose-6-phosphate (G-6-P) in the muscle which may have caused the reduced uptake of glucose. Glucose-6-P inhibits hexokinase $(E C 2.7 .1 .1)$ which phosphorylates glucose. The authors suggested that the increased G-6-P and lactate resulting from feeding the CHO diet may have reflected the higher glycogen concentrations, as the rate of glycogen catabolism is related to resting glycogen concentrations. High lactate and alanine concentrations were also observed when feeding the fat diet and may have been related to decreased oxidation of pyruvate owing to the inhibition of pyruvate dehydrogenase $(\mathrm{PDH})$ by FA oxidation (Essén-Gustavsson et al. 1991). Alternative feedstuffs and roughage sources for the working horse have been evaluated for their efficacy in providing suitable energy substrates. A high fibre diet of cubed lucerne:corn plant had no effect on performance parameters such as heart rate, respiration rate and lactate concentrations during or following exercise, but blood glucose concentration was higher during recovery than in horses on a conventional diet (Younglove et al. 1994). Roughage source, either lucerne or non-lucerne roughage diets, also had no effect on cardiorespiratory and metabolic function during or after exercise. Roughage source also had no effect on endurance performance (Southwood et al. 1993). Fescue hay infested with edophyte fungus was fed to exercising yearling horses with no reported detrimental effects (Pendergraft \& Arns, 1993). Donkeys exercised on a straw diet had increased lactate concentrations during exercise and became more hypoglycaemic than those fed hay diets. They also had higher heartrate during exercise and lower $\mathrm{V}_{\mathrm{O}_{\text {max }}}$ (Mueller et al. 1995). Straw or low quality hay diets should therefore be avoided for high performance athletes but other non-traditional feedstuffs may be suitable for them. 


\section{THE FAT SUPPLEMENTED DIET}

The efficacy of feeding fat supplemented diets to performance horses has been the focus of many investigations recently. Fat itself is readily digested and absorbed by the horse, with vegetable sources having better utilization than animal fats (Rich et al. 1981). Fat has been included up to $20 \%$ of the diet without having negative effects on intake or digestibility of dry matter and energy (Sweeny et al. 1995; Hughes et al. 1995; Julen et al. 1995). Addition of fat to the diet increases the energy density, thereby allowing a decrease in percentage of the diet as concentrate or a reduction in total feed intake while maintaining the animal in positive energy balance; this becomes critically important in hard working horses which cannot consume enough food on a traditional diet to meet their energy needs. Furthermore, fat has actually been found to reduce the energy required for maintenance, increasing the efficiency in use of DE regardless of the animal's body condition or environmental temperature (Potter et al. 1990). Supplemental fat may decrease the energy needed for thermoregulation, as added fat reduced thermal stress in exercising Thoroughbreds compared with controls (Scott et al. 1993). Substitution of fat for carbohydrates apparently reduced the thermal load on the horses by decreasing the heat produced from fermenting starch in the large intestine. Therefore, feeding fat to exercising horses may be advantageous in hot, humid climates.

Besides providing an effective means of increasing energy density in the diet while decreasing thermal stress, supplemental fat has been reported to increase performance in animals undergoing both submaximal and intense exercise. Some authors have observed that feeding fat to performance horses has improved race times (Harkins et al. 1992), and lengthened time to fatigue (Eaton et al. 1995b). Oldham et al. (1990) found that the speed of horses fed a fat supplemented diet and worked at a constant heart rate was increased compared to controls in the last two intervals of an exercise test consisting of four $600 \mathrm{~m}$ gallops.

There are conflicting reports which show no efficacy of feeding fat to improve performance of horses. Discrepancies in results may be due to the amount and type of fat fed, the contents of the basal diet, the length of fat supplementation, the particular training regimen, or the intensity of the exercise test. The following will attempt to provide a general understanding of the effects of feeding fat in relation to study protocols.

Adding fat to the diet apparently alters metabolism of energy substrates during both aerobic and anaerobic exercise. Fat oxidation may provide the majority of the energy during submaximal exercise, with the remainder being supplied by blood glucose and liver or muscle glycogen. One of the suggested effects of adaptation to a fat supplemented diet is an elevation of plasma NEFA concentrations, a subsequent increase in FA oxidation and decreased reliance on muscle glycogen and blood glucose for energy substrates. In this case, feeding fat to an athlete undergoing prolonged aerobic exercise would clearly be advantageous. The potential benefits to the anaerobically exercising individual, however, are not so apparent.

Kronfeld et al. (1994) suggested that the rate of glycolysis may be slowed after fat adaptation owing to an increase in production of citrate, a metabolite of FA oxidation. Increased concentrations of citrate will inhibit phosphofructokinase, one of the rate limiting enzymes of glycolysis (Holloszy \& Coyle, 1984). Limited phosphofructokinase activity will result in accumulation of G-6-P, which will in turn result in negative feedback on glucose and glycogen utilization. Decreased rates of glycolysis at rest would theoretically facilitate increased muscle glycogen storage. As glycogen is the primary substrate during intense exercise, these additional stores of glycogen might then be available for use during anaerobic exercise and subsequently delay the onset of fatigue. Studies have shown that 
when horses were fed 10-12\% fat in the diet, resting muscle glycogen increased (Oldham et al. 1990; Jones et al. 1991; Harkins et al. 1992; Scott et al. 1992; Hughes et al. 1995). Others have seen no change when lower amounts of fat were fed (Eaton et al. 1995b). Increasing fat to $15 \%$ of the diet decreased glycogen stores compared to control animals (Pagan et al. 1987). While the reason for this drop in muscle glycogen is not understood, there seems to be an upper limit to the effectiveness of increasing glycogen stores by increasing the percentage of fat in the diet. There also appears to be a need for an adequate amount of $\mathrm{CHO}$ in the diet to supply the necessary substrates for glycogen synthesis. Fat cannot be used in gluconeogenesis, at least not at a practical rate (Murray et al. 1993).

Body condition has also influenced the effects of added dietary fat. Studies with Thoroughbreds and Miniature Horses fed a fat supplemented diet have shown that animals in moderate body condition had greater muscle glycogen stores following fat adaptation than those in low body condition (Jones et al. 1991; Scott et al. 1992).

Despite the effect of feeding moderate levels of fat to increase resting muscle glycogen stores, results have not been consistent concerning glycogen utilization during exercise. Fat supplemented horses have been found to store and mobilize greater amounts of glycogen during anaerobic exercise on a treadmill (Jones et al. 1991), sprinting (Oldham et al. 1990; Scott et al. 1992; Hughes et al. 1995), or carrying out simulated cutting performances utilizing a mechanical cow (Julen et al. 1995). However, in other horses fed fat and performing a $1600 \mathrm{~m}$ race, muscle glycogen in fat supplemented horses was higher both before and after a race in comparison with controls, but the rate of glycogen utilization was the same (Harkins et al. 1992). Eaton et al. (1995b) did not report any improvement in glycogen storage or in glycogen utilization from feeding fat during an incremental exercise test to fatigue. However, the horses were only fed $12 \%$ of the digestible energy as fat. Variations in the above results are likely because of differing experimental protocols and the amount of fat supplemented in the diet.

If adaptation to a fat supplemented diet increases glycogen storage and utilization, it should be reflected in increased lactate accumulation in the blood following intense exercise resulting from anaerobic glycolysis. An increase in the utilization of fat as an energy source may also increase blood lactate concentrations. An increase in FA oxidation will cause an increase in acetyl CoA production. This in turn inhibits pyruvate dehydrogenase, causing an increase in pyruvate concentrations (Murray et al. 1993), and this additional pyruvate is then converted to lactate during a state of oxygen deficiency. Sprint trained horses fed a $10 \%$ corn oil diet had increased lactate accumulation during repeated sprints (Ferrante et al. 1993, 1994b; Taylor et al. 1993; Kronfeld et al. 1994). Lactate concentrations were higher following an exercise bout at velocities above $\dot{V}_{\mathrm{o}_{\text {amax }}}$ in horses fed $12 \%$ of DE as fat (Eaton et al. 1995 b). Peak plasma lactate after exercise tended to be higher in Miniature Horses fed fat (Jones et al. 1991), and Oldham et al. (1990) observed a trend to increased mean lactate concentrations in racehorses after repeated sprints when horses were adapted to a fat supplemented diet and glycogen stores were increased. Custalow (1993) also found an increase in lactate threshold (the speed of work intensity at which lactate concentrations begin to increase) and lactate concentrations before reaching the threshold with fat supplementation, but the effect was not significant. Moser et al. (1991) found no effect on lactate production when horses fed low levels of fat underwent submaximal exercise. This would be expected if horses were exercising beneath their lactate threshold. There was no effect of feeding fat on blood lactate concentrations when horses completed a simulated cutting test (Julen et al. 1995), a $1600 \mathrm{~m}$ race (Harkins et al. 1992), repeated sprints (Scott et al. 1992) or worked at high altitudes (Wickler et al. 1995). When blood lactate concentrations are very high following intense exercise, small differences due to diets may be more difficult to observe than when smaller amounts of lactate are produced. 
Differences in results from feeding fat to exercising horses may be due to the type of fat fed and exercise intensity. The type of fat fed may also affect a metabolic response. Pagan et al. (1993) fed a concentrate containing $10 \%$ added fat in the form of soyabean oil, coconut oil or a 50:50 mixture of the two oils. The control diet was a traditional high starch, pelleted diet composed mainly of corn and oats. $V_{200}$, the velocity achieved at a heart rate of $200 \mathrm{bpm}$, was higher when the soya oil diet was fed $v$. the coconut or mixed oil diet. Plasma NEFA concentrations were higher in horses fed the coconut oil diet $v$. the control. VLA, the velocity at which blood lactate reaches $4 \mathrm{mmol} / \mathrm{l}$, was lower in the control group when compared to all three fat supplemented diets. In addition blood $\mathrm{NH}_{3}$ was found to be lower in the group fed coconut oil. Plasma lactate concentration was lower after an 8 min gallop in animals supplemented with coconut oil $v$. control horses, but horses fed soyabean oil or mixed oil were not different from controls (Pagan et al. 1993). However, when the horses were exercised at top speeds, plasma lactate concentrations were $56 \%$ higher in the control group than in the mixed oil group. The author concluded that this may be due to the large percentage of saturated and medium chain FA in coconut oil which may be mobilized and oxidized quickly. It may have also been due to differences in carbohydrate intake. Sprint trained horses fed a diet that included a 50:50 mixture of corn oil and lecithin at 14\% of the diet by weight had lowered blood lactate concentrations during anaerobic exercise, contrasting with previous results by this author (Taylor et al. 1995). Addition of lecithin may have reversed previous results by increasing fatty acid transport and oxidation, thereby reducing glycolysis.

The fat content of the diet may also alter glycaemic responses to feeding. Pagan et al. (1995c) found that horses fed a meal with added soyabean oil had lower concentrations of blood glucose than controls until $3 \mathrm{~h}$ after feeding and then increased blood glucose concentrations over controls at $6 \mathrm{~h}$ after feeding. After $8-10 \mathrm{~h}$ following feeding, insulin concentration was higher in the fat fed animals (Pagan et al. 1995c). These results were reportedly independent of starch intake. Feeding oil also decreased the peak of glucose and insulin concentrations after feeding and prevented the decline in plasma glucose concentrations caused by strenuous exercise performed $4 \mathrm{~h}$ after feeding (Pagan et al. $1995 a$ ). However, fat did not prevent a decrease in plasma glucose concentrations when horses were trotted for $30 \mathrm{~min}$ at slow speeds (Pagan et al. 1995 a). These results were not reproducible in additional studies using a similar exercise test and other sources of fat (Pagan et al. 1993, 1995 b), nor was there a decrease in glucose concentrations during exercise performed $8 \mathrm{~h}$ after feeding (Pagan et al. 1995 b). Mean blood glucose concentrations were higher during an exercise test of repeated sprints in horses fed supplemental fat (Oldham et al. 1990) and in horses subjected to repeated exercise at high altitudes (Wickler et al. 1995). A similar exercise test to Oldham's study did not result in differences in blood glucose concentrations between control and fat supplemented horses (Scott et al. 1992) nor was there a difference due to fat supplementation in glucose concentrations in Miniature Horses exercised for a short duration on a treadmill (Jones et al. 1991). Fat adapted horses performing a $1600 \mathrm{~m}$ race had higher glucose concentrations before and immediately after exercise when deprived of the normal morning meal (Harkins et al. 1992). However, Moser et al. (1991) found that while blood glucose concentrations increased in response to exercise, there was no difference between control and fat supplemented diets. This may have been due to the low level of fat supplementation $(6 \%$ of the diet) and exercise being performed after an overnight fast. The glucose threshold was increased in interval trained horses fed 10\% fat (Custalow, 1993), but full metabolic adaptation did not take place until 11 weeks of the training regimen. In summary, there is no clear, consistent post-feeding glycaemic response to fat supplementation in exercising 
horses. This is probably due to the glucose homeostasis mechanisms in the body and to the wide variety of experimental protocols reported.

Adding fat to the diet may also alter the NEFA and lipoprotein profiles in the plasma. Plasma NEFA concentrations are proportional to their rate of turnover and are believed to be the primary source of FA for exercising muscle (Lawrence, 1994). NEFA concentrations increased after exercise in pack animals, and animals on a high fat diet had elevated NEFA concentrations following the most strenuous exercise test compared to controls (Wickler et al. 1995). Higher concentrations of plasma NEFA could result in increased fat oxidation and reduced glucose oxidation as horses that were infused with NEFA prior to exercise had lower $R Q$ indicative of greater fat utilization during low intensity exercise when compared with controls (Orme et al. 1995). While intense submaximal exercise did cause a decrease in NEFA concentration during exercise and an increase in concentration during recovery, there was no effect of diet composition (Moser et al. 1991). When cutting horses were fed a $10 \%$ fat supplemented concentrate for 28 days, plasma oleate concentrations appeared higher on $\mathrm{d} 14$ and 28 while linoleate was higher in fat fed animals on $\mathrm{d} 28$ at rest and after exercise. Plasma stearate and palmitate concentrations were unaffected (Julen et al. 1995). The effect of fat supplementation on circulating lipoproteins in the exercised and sedentary horse has also been examined (Kurcz et al. 1993). After 3 weeks on a diet containing $20 \%$ of the DE as corn oil, low density lipoprotein (LDL) and cholesterol concentrations were lower in the exercised animals compared to sedentary animals while after 6 weeks of fat adaptation, very low density lipoprotein (VLDL) and triacylglycerol concentrations were also lowered in the exercised group. Fat adaptation may involve decreased VLDL production by the liver or increased lipoprotein lipase (EC 3.1.1.34) activity in the conditioned animal.

At the cell level, dietary fat supplementation may affect the efficiency of the sarcoplasmic reticulum (SR), the intracellular storage site for calcium, during muscular contraction. CaATPase, the enzyme responsible for regulating $\mathrm{Ca}$ transport across the membrane, may be dependent on the amount of phospholipid in the membrane. Wilson et al. (1995) showed tinat CaATPase activity in fat fed horses was lower after exercise. Therefore, fat may act to increase resting SR function and its response to exercise.

Adaptation to a fat supplemented diet may benefit the exercising horse by altering blood gas concentrations. Fat oxidation would be reflected in lowered RQ compared with $\mathrm{CHO}$ oxidation owing to decreased carbon dioxide production. Decreased $P_{\mathrm{Co}_{2}}$ may aid in alleviating the drop in blood $\mathrm{pH}$ that may contribute to fatigue. Plasma $\mathrm{P}_{\mathrm{CO}_{2}}$ decreased faster during sprints in fat fed horses compared with controls and attenuated the rise in plasma $\left[\mathrm{H}^{+}\right]$(Ferrante et al. 1994a) but a similar effect was not seen by others (Taylor et al. 1993). Interpreting and comparing the results of studies with such a wide range of experimental protocols is difficult at best. Within the reviewed papers, there was a considerable variation in the amount of fat fed, being expressed in ranges of $10-12 \%$ by weight of the total diet, $10-12 \%$ by weight of the concentrate portion, $12-20 \%$ of total DE in the diet, etc. In addition, control diets were also varied between being held isocaloric and isonitrogenous, to fat being topdressed to the control ration, to elimination of roughage from the experimental diet. Such confounding factors make determination of the effects of feeding supplemental fat from one study to the next challenging.

As mentioned previously, training regimens may also affect results. Some horses were conditioned aerobically and tested at anaerobic work levels while other protocols included anaerobic conditioning. Aerobic conditioning would have little effect on alteration of the fast twitch, highly glycolytic fibres used in explosive exercise.

A wide variety of experimental protocols used to study the efficiency of fat supplemented dieis have been reported and they were discussed along with their limitations. On the 
surface it might seem sensible to standardize protocols between researchers, but in reality such standardization of methods would probably be impossible. Each experiment was designed with a different goal and a different set of questions in mind. Therefore, the nature of this research demands alterations between studies, though inconvenient to the reader.

\section{PROTEIN REQUIREMENTS AND METABOLISM}

Protein is one of the most costly components of the diet and often attracts the most attention from owners and trainers. Frequently, trainers apparently select feed not on the energy content but rather on the percentage of protein in the feed. Protein is believed to supply only 5-15\% of the energy used during exercise (Lawrence, 1994). Many believe that feeding large amounts of protein can increase performance, but this idea has not been substantiated. The National Research Council (1989) recommendations for dietary protein concentrations for the exercising horse are $9.8 \%$ for light work, $10.4 \%$ for moderate work and $11.4 \%$ for intense work. Feeding protein above these amounts, however, is a common practice. A survey of Standardbred and Thoroughbred racing stables showed that the mean crude protein (CP) concentrations in feeds, on a dry matter basis, were $14.5 \%$ and $13.8 \%$ respectively (Gallagher et al. 1992a,b) which is well above NRC (1989) suggested requirements.

Some authors have made claims that might encourage these practices, describing an increased protein need for the exercising horse. Schott et al. (1995) reported that exercise increased the excretion of nitrogen, indicating increased protein catabolism and perhaps a greater requirement in the exercising horse. This phenomenon was transient and was not associated with lasting changes in renal function. In a review by Custalow (1991), increased $\mathrm{CP}$ intake was said to decrease plasma lactate accumulation. She also stated that intensely exercised horses can lose 25-37.5 g nitrogen via the sweat in extreme situations. Plasma concentrations of amino acids also decrease during chronic submaximal exercise, which may indicate greater need for protein during exercise (McKeever et al. 1986; cited by Custalow, 1991). Other studies have shown an increase in free lysine and phenylalanine concentrations after exercise (Pösö et al. 1991; Miller-Graber et al. 1990). As these are essential amino acids not normally catabolized for energy, it indicated that net protein catabolism was taking place. Miller-Graber et al. (1991a) observed a decrease in urea-N excretion with exercise which contrasted with other results.

To determine if protein requirements of the exercising horse are greater than the NRC recommendations, Miller-Graber et al. $(1991 b, c)$ conducted an exercise test after feeding two amounts of protein. The control diet consisted of $9 \% \mathrm{CP}$ and the high protein diet contained $18.5 \% \mathrm{CP}$. The exercise test was performed at $60 \% \mathrm{~V}_{\mathrm{O}_{2 \max }}, 2 \mathrm{~h}$ after a meal. There was no effect of diet on hepatic or intramuscular glycogen utilization, plasma lactate, $\mathrm{O}_{2}$ uptake or plasma NEFA concentrations. However the lactate: pyruvate ratio was higher in horses fed the control diet, indicating that the interconversion of lactate and pyruvate may be influenced by dietary protein (Miller-Graber et al. 1991 c). The animals on the high protein diet had lower plasma $\mathrm{NH}_{3}$ concentrations but had increased urea- $\mathrm{N}$, increased total body urea- $\mathrm{N}$ and increased urea- $\mathrm{N}$ present in the sweat. The horses on the high protein diet may have had an improved ability to convert ammonia to urea. However, the high protein diet also resulted in an increase in the orotic acid:creatine ratio. The authors concluded that the protein supplied by the diet exceeded the animals' ability to synthesize urea efficiently, being beyond the capacity of the urea cycle (Miller-Graber et al. 1991 b). Others have also suggested that excess protein may be detrimental. Excessive $\mathrm{N}$ intake resulted in increased water intake and increased $\mathrm{NH}_{3}$ excretion (Meyer, 1987; cited by 
Hintz, 1994). High concentrations of $\mathrm{NH}_{3}$ in the environment of the stabled horse could contribute to respiratory problems. As a practical matter, any increased protein needs due to exercise are probably met by the required increase in feed intake if the diets are kept at the same protein:calorie ratio.

Exercise apparently alters the metabolism of amino acids. Total plasma amino- $\mathrm{N}$ increased with intense exercise and long term exercise to fatigue (Jahn et al. 1991; Pösö et al. 1991). Rises in plasma alanine concentrations during exercise have repeatedly been observed (Miller-Graber et al. 1990, 1991 b; Jahn et al. 1991; Pösö et al. 1991) with a reciprocal relationship existing between plasma alanine and glutamate. This relationship is explained by the familiar glucose-alanine cycle. In the process of gluconeogenesis, alanine is an important precursor of glucose. Both submaximal and intense activity result in an increase in pyruvate. Pyruvate is transaminated to alanine via the conversion of glutamate to $\alpha$-ketoglutarate, which can then be utilized for energy via entry into the TCA cycle, and glucose can be formed from alanine. In the liver, alanine is converted back to pyruvate and then glucose. The synthesis of alanine from pyruvate may therefore be of importance in aerobic metabolism if the glucose-alanine cycle is activated to provide energy (MillerGraber et al. 1990; Pösö et al. 1991). Glutamate concentrations can also be $\mathrm{r}$ ¿duced by the addition of $\mathrm{NH}_{3}$ to form glutamine. Glutamine serves as an ammonia a ceptor in the exercising muscle. Plasma glutamine concentration was increased following an exercise test above $60 \% \dot{V}_{\mathrm{O}_{2, \max }}$ (Miller-Graber et al. 1991 b) while Pösö et al. (1991) found an increase in plasma glutamine concentration only after an exercise test to fatigue and not following short term, anaerobic activity. Intramuscular glutamine concentrations also did not increase until after the exercise test to fatigue (Pösö et al. 1991). During exercise, the branched chain amino acids are readily deaminated and oxidized to provide energy. The concentrations of branched chain amino acids have been found to increase significantly in the plasma as well as intramuscularly (Miller-Graber et al. 1991 b; Pösö et al. 1991). Jahn et al. (1991) also saw an increase in plasma leucine concentration with exercise. Valine is glycogenic, leucine is ketogenic while isoleucine is catabolized to both ketogenic and glycogenic compounds (Murray et al. 1993). Many of the reactions involved closely resemble the reactions of straight and branched chain FA catabolism. It has been reported that exercise stimulates the breakdown of liver proteins which may then be catabolized or used to build new proteins (Glade, 1991). Provision of exogenous sources of amino acids may alleviate protein degradation in the body. Amino acid supplementation consisting of the branched chain amino acids, glutamine and carnitine resulted in lower plasma lactate accumulation and lower heart rates in treated horses $v$. controls when given 30 min prior to exercise (Glade, 1991). However, results of this study are difficult to interpret as the amino acids were given together, rather than separately, as would be needed to determine which amino acids, or combinations of amino acids, might have actually been causing the effect.

In summary, results of several studies indicate that amino acid metabolism in working muscle may contribute to energy production in comparison to the resting state. Thus, more work is needed to define the specific role of amino acid metabolism in the exercising horse.

\section{NITROGENOUS COMPOUNDS AS ERGOGENIC AIDS}

Carnitine, a low molecular weight quaternary amine, is essential for the transport of fatty acids across the mitochondrial membrane as well as the regulation of the acetyl CoA:CoA ratio within the membrane (Murray et al. 1993). Therefore, it may be a rate limiting factor for fat utilization during exercise. Efforts at improving performance in the horse with 
carnitine supplementation have not been fruitful. L-Carnitine is poorly absorbed by the horse as $10 \mathrm{~g}$ carnitine given via nasogastric intubation or consumed in the feed had little effect on plasma concentrations and no effect on muscle carnitine (Harris et al. 1995). This is despite the fact that the amount of carnitine administered was enough to replace the entire carnitine pool in the body. Harris concluded that normal plasma carnitine concentrations are sufficient in the mature, well fed horse. In addition, there was no change in carnitine content of muscle following intense exercise (Foster \& Harris, 1992). In the light of these findings, carnitine supplementation does not appear to be a promising area for research or application in the diet of racehorses.

Trimethylglycine has also been fed to horses in an attempt to reduce lactate accumulation and delay fatigue (Warren et al. 1995). Trimethylglycine is chemically similar to dimethylglycine which has been proposed to decrease lactate production. Therefore it was suggested to have the same activity (Warren et al. 1995). Trimethylglycine was supplemented at $80 \mathrm{mg} / \mathrm{kg}$ daily in a crossover design for 14 days to trained and untrained horses. After the feeding period the horses performed an incremental exercise test. Trimethylglycine had no effect in the trained horse, but appeared to increase lactate clearance rate in the non-conditioned horse (Warren et al. 1995).

Monosodium glutamate (MSG) was provided to horses by Beaunoyer et al. (1991) to aid in the detoxification of $\mathrm{NH}_{3}$ and increase transamination of pyruvate to alanine and $\alpha$-ketoglutarate. Monosodium glutamate had no effect on run time to fatigue, but did decrease $\mathrm{NH}_{3}$ concentrations in the blood. The authors attributed this reduction to an increase in urea cycle activity and an increase in production of glutamine, asparagine and alanine. Although no definite effects on delaying fatigue were seen, MSG did decrease accumulation of $\mathrm{NH}_{3}$ which may reduce its negative effects on metabolism. However, when ammonium acetate was directly infused into horses, there was no decrease in performance, indicating that increased concentrations of $\mathrm{NH}_{3}$ in plasma do not contribute to fatigue (Miller-Graber et al. $1991 \mathrm{a}$ ). In addition, there was no correlation between gallop time and post-gallop $\mathrm{NH}_{3}$ accumulation, again indicating that $\mathrm{NH}_{3}$ is probably not a direct cause of fatigue (Harris et al. 1991).

Other avenues of research have investigated the performance enhancing ability of creatine. Creatine serves to regenerate ATP at the contractile site of the muscle and transfer energy from the mitochondria (Powers \& Howley, 1994). It may also function to buffer $\mathrm{H}^{+}$. Sewell \& Harris (1995) found that mean resting plasma creatine concentrations differ greatly between horses, with a range of $8-103 \mu \mathrm{mol} / 1$. Nasogastric infusion of creatine at $0.05 \mathrm{~g} / \mathrm{kg}$ body weight increased plasma creatine concentration, but feeding creatine at $0.15 \mathrm{~g} / \mathrm{kg}$ for $13 \mathrm{~d}$ had little effect on plasma concentrations and no effect on muscle creatine or ATP concentrations. The authors suggested that the lack of response in muscle creatine concentrations may have been due to the failure to increase plasma creatine concentration sufficiently.

\section{USE OF BUFFERING AGENTS}

One of the goals of current research is to delay fatigue through dietary manipulation. As mentioned previously, muscular acidosis is frequently assumed to be a major contributor to fatigue. The development of acidosis in the muscle may be delayed by decreasing the rate at which lactate and $\mathrm{H}^{+}$are produced, increasing the movement of lactate out of the muscle, or by buffering the increased concentrations of $\mathrm{H}^{+}$. An increase in $\mathrm{pH}$ or buffering capacity in the systemic circulation could serve to alleviate the negative effects of muscular acidosis by causing greater efflux of lactate and $\mathrm{H}^{+}$from the muscle cell. The major proton acceptor in the body is the bicarbonate system (Powers \& Howley, 1994). Hydrogen ions associate 
with $\mathrm{HCO}_{3}{ }^{-}$and form carbonic acid which may further break down to form $\mathrm{CO}_{2}$ and $\mathrm{H}_{2} \mathrm{O}$ (Powers \& Howley, 1994). Bicarbonate concentration is regulated primarily by the kidneys and lungs, but may be affected by other buffer systems and dietary cation anion balance (Ralston, 1994). Therefore, augmentating a horse's natural buffering system by dosing them with sodium bicarbonate has been thought to enhance performance of racehorses by delaying the onset of fatigue in the final stages of maximal exertion.

Lawrence (1994) reported that during the late 1980s and early 1990 s the practice of administering a solution of sodium bicarbonate via nasogastric intubation, termed 'milkshakes', became quite popular, especially in racing Standardbreds. The efficacy of this treatment for improving performance or race times has not been proven consistently. Lawrence et al. (1990) found race times to be $1 \cdot 1 \mathrm{~s}$ faster in Standardbreds dosed with $300 \mathrm{mg} \mathrm{NaHCO} / \mathrm{kg}$. However, in this study eight horses had faster race times with the $\mathrm{NaHCO}_{3}$ treatment, while six of the horses had faster times with the control treatment. Frey et al. (1995), Harkins \& Kammerling (1992) and Greenhaff et al. (1991) saw no improvement in race times, and run time to fatigue was not affected by dosing with $\mathrm{NaHCO}_{3}$ (Lloyd \& Rose, 1995). Lloyd et al. (1993) improved run time to fatigue in horses with $\mathrm{NaHCO}_{3}$ administration when compared with horses given $\mathrm{NaCl}$, but bicarbonate depressed performance relative to controls receiving no treatment. Shorter run time to fatigue may be explained by the bicarbonate treated horses carrying a greater weight load than the control horses as they were allowed free access to water after treatment. The improved performance over saline treatments may have been caused by $\mathrm{NaCl}$ induced metabolic acidosis. Hinchcliff et al. (1993 b) reported metabolic acidosis with administration of $\mathrm{NaCl}$. Therefore, it is the anion of the compound that affects the $\mathrm{pH}$ response.

Metabolic responses to $\mathrm{NaHCO}_{3}$ loading have been highly consistent among researchers, causing definite acid-base changes and induced metabolic alkalosis. Blood $\mathrm{pH},\left[\mathrm{HCO}_{3}{ }^{-}\right]$, and standardized base excess (BE) were higher in $\mathrm{NaHCO}_{3}$-dosed horses at rest (Corn et al. 1991; Greenhaff et al. 1991; Jahn et al. 1991; Roberts et al. 1991; Harkins \& Kammerling, 1992; Hanson et al. 1993; Lloyd et al. 1993; Frey et al. 1995). However, in a subsequent study using Miniature Horses Corn et al. (1995) did not observe a significant increase in $\mathrm{pH}, \mathrm{HCO}_{3}{ }^{-}$or $\mathrm{BE} 3 \mathrm{~h}$ after dosing with $400 \mathrm{mg} / \mathrm{kg}$. The effects of $\mathrm{NaHCO}_{3}$ were not observed until the recovery period following an exercise test. In other studies, animals dosed with $\mathrm{NaHCO}_{3}$ were in metabolic alkalosis and had increased lactate concentrations during (Roberts et al. 1991; Ferrante et al. 1993) and after a submaximal or intense exercise test (Greenhaff et al. 1991; Roberts et al. 1991; Harkins \& Kammerling, 1992; Corn et al. 1995; Frey et al. 1995; Lloyd \& Rose, 1995). However, horses on a low fibre, high soluble carbohydrate diet did not exhibit the same effect of increased $\mathrm{pH}$ or lactate concentration after exercise with dietary sodium bicarbonate supplementation (Ferrante et al. 1992). The particular exercise test that was used in this study may not have been of sufficient intensity, as lactate concentrations were lower in both treatment and control groups after exercise. Greenhaff et al. (1991) also found that $\mathrm{NH}_{3}$ concentrations were lower with $\mathrm{NaHCO}_{3}$ treatment. They suggested that metabolic alkalosis may delay the onset of fatigue during high intensity exercise by decreasing the extent of adenine nucleotide loss, which is reflected by plasma $\left[\mathrm{NH}_{3}\right]$. As mentioned previously, lowered $\left[\mathrm{NH}_{3}\right]$ may also be beneficial as $\mathrm{NH}_{3}$ could hasten fatigue by increasing pyruvate concentrations which are subsequently converted to lactate.

Different dosages and times of administration may be the key component to differences in results from administration of $\mathrm{NaHCO}_{3}$. Peak buffering capacity has been observed 4-6 h after treatment (Corn et al. 1991; Greenhaff et al. 1991; Harkins \& Kammerling, 1992; Hanson et al. 1993; Kline et al. 1993; Lloyd \& Rose, 1995). Therefore exercise tests should be conducted within this time span to achieve maximal effectiveness from 
administration. In addition, bicarbonate dosages have ranged from $0.3 \mathrm{~g} / \mathrm{kg}$ to $1 \mathrm{~g} / \mathrm{kg}$ between studies with larger amounts of $\mathrm{NaHCO}_{3}$ increasing the degree of alkalosis. Miniature Horses given varying amounts of $\mathrm{NaHCO}_{3}$ had higher $\mathrm{pH}$, base excess and $\left[\mathrm{HCO}_{3}{ }^{-}\right]$with $400 \mathrm{mg} / \mathrm{kg}$ than with $200 \mathrm{mg} / \mathrm{kg}$ body weight (Corn et al. 1991), and Lloyd \& Rose (1995) also observed a larger $\left[\mathrm{HCO}_{3}\right]$ with $1.0 \mathrm{~g} / \mathrm{kg}$ than with $0.5 \mathrm{~g} / \mathrm{kg}$. However, there does seem to be a limit to response, as doubling the dose from $0.5 \mathrm{~g} / \mathrm{kg}$ to $1.0 \mathrm{~g} / \mathrm{kg}$ did not double plasma $\left[\mathrm{HCO}_{3}^{-}\right.$] (Lloyd \& Rose, 1995).

In addition to an absence of reports of substantially improved performance, $\mathrm{NaHCO}_{3}$ administration may be detrimental to the health of the animal. Numerous studies have shown that administration of $\mathrm{NaHCO}_{3}$ alters the status of other important electrolytes. Hanson et al. (1993) found that treatment with bicarbonate lowered plasma [K], [Ca], and $[\mathrm{Cl}]$ while increasing [Na]. Other authors have also reported hypokalaemia after administration of $\mathrm{NaHCO}_{3}$ (Corn et al. 1991, 1995; Kline et al. 1993; Frey et al. 1995). The decrease in $[\mathrm{K}]$ is thought to be due to the exchange of extracellular $\mathrm{K}$ for intracellular $\mathrm{H}^{+}$ in response to metabolic alkalosis. It may also be due to increasing intracellular $\mathrm{K}$ in the presence of increased extracellular $\mathrm{Na}$. The decrease in $[\mathrm{Cl}]$ was attributed to increased excretion in response to the presence of additional anions. Further alterations in mineral status due to heat stress, dehydration and administration of diuretics could compound these changes. In the study by Frey et al. (1995) horses had visible signs of distress after administration of 'milkshakes', including diarrhoea, synchronous diaphragmatic flutters and epistaxis. In consideration of these results the use of $\mathrm{NaHCO}_{3}$ dosing in horses should be discouraged. Several racing authorities apparently have banned its usage as it could be deceptive to the betting public.

Other alternatives to $\mathrm{NaHCO}_{3}$ for increasing the buffering capacity of protons have been explored. Carnosine, a dipeptide of $\beta$-alanine and histidine, is found in high concentrations in the equine skeletal muscle (Miller-Graber et al. 1990), and is thought to be important in intracellular buffering of $\mathrm{H}^{+}$. Carnosine is believed to contribute $30 \%$ of the physicochemical buffering in the cell and occurs in higher concentrations in Type II muscle fibres (Sewell et al. 1992). Type II fibres are the fast responding, high power output muscle fibres recruited during maximal exertion. Buffering capacity of muscle fibres was directly correlated with carnosine content and would therefore be greater in Type II fibres (Sewell et al. 1992). During high intensity work, a high rate of glycolysis would necessitate this greater buffering capacity. Anecdotally, Miller-Graber et al. (1990) observed that horses with the longest time to fatigue also had the highest carnosine content within the muscle. With these findings in mind, attempts have been made to increase the buffering capacity of the muscle and improve its ability to deal with acidosis by providing supplemental carnosine or histidine. Histidine supplementation could theoretically increase muscle carnosine as it is one of the amino acids in the dipeptide. Feeding diets containing graded levels of histidine at $0.25,0.36,0.45$, and $0.56 \%$ resulted in a dose dependent response in plasma histidine concentrations (Miller-Graber \& Syers, 1993). However, no response was seen in intramuscular histidine, $\beta$-alanine or carnosine concentrations, suggesting that the animals' requirement for histidine was already met at $0.25 \%$ of the diet. When Powell et al. (1991) used treatments of $0.14 \%$ and $0.40 \%$ histidine, they found a non-significant increase of $19 \cdot 2 \%$ in muscle carnosine concentration on the $0.40 \%$ diet. Horses in this study performed a standard exercise test and an exercise bout to fatigue after which blood lactate concentrations were slightly higher in the supplemented horses, probably owing to slightly longer time to fatigue. Improving athletic performance by enhancing carnosine stores may not be possible as Harris et al. (1991) found no significant change in muscle carnosine content in Thoroughbred horses after undergoing maximal and submaximal exercise. Therefore, carnosine may not be a limiting factor in the performance of the horse. 


\section{WATER AND ELECTROLYTES}

Water is often overlooked when nutritional requirements are considered by many horsemen. However, it should be among the most important considerations in the exercising horse. Increase in blood viscosity, packed cell volume (PCV) and total plasma protein reflect not only the release of blood cells by the spleen, but also the loss of water from the vascular system to the intracellular and interstitial fluid (Coyne et al. 1990; White et al. 1991; Naylor et al. 1993; Sommerdahl et al. 1994; Carlson, 1995). This fluid shift occurs very rapidly, within 30-60 s after the onset of exercise (Carlson, 1995). Additional water is lost from the animal as sweat. At least two-thirds of the metabolic heat load is dissipated through the sweat, and losses of $101 / \mathrm{h}$ have been reported (Hodgson et al. 1994). Dehydration can limit the conductance of heat from the core to the periphery and limit the ability of the animal to dissipate heat properly (Hodgson et al. 1994). Water losses in 3-d eventing horses persisted for 18-24 h after completion of phase D (Andrews et al. 1993). Providing $\mathrm{NaCl}$ prior to exercise may improve water balance by increasing water intake (Coenan et al. 1995).

Feeding prior to exercise may also improve the hydration of the animal. Absorption of fluid from the gastrointestinal (GI) tract may counteract the effects of excessive sweating and prevent dehydration. The composition of the diet may influence the amount of water available to the horse for absorption. Feeding hay increased the amount of water in the gut when compared to a mixed ration (Meyer, 1995). Water intake was also greater in horses fed a complete hay diet $v$. those on a hay-concentrate diet (Danielson et al. 1995). Therefore the gut may be able to act as a reservoir for water and electrolytes for horses undergoing sustained exercise where sweat losses are high. However, such a feeding practice may not be advantageous in horses undergoing short term exercise as it would increase the weight and thus the work load on the animal.

Though not a major component of diets, electrolytes have the ability to affect a horse's performance dramatically. Exercise results in altered acid-base status not only by the production of lactate but also by changes in plasma concentrations of ions such as $\mathrm{Na}^{+}, \mathrm{K}^{+}$, $\mathrm{Cl}^{-}$, etc. Such changes are primarily in response to the fluid shift and to losses in the sweat. Exercise may also cause alterations in aldosterone (Hower et al. 1995) the primary mineralocorticoid which functions to conserve water and $\mathrm{Na}$ and remove excess $\mathrm{K}$. Hower et al. (1995) found an increase in aldosterone with exercise which corresponded to an increase in plasma $[\mathrm{K}]$. Plasma $\mathrm{K}$ and aldosterone concentrations were also higher during exercise performed in the summer than in the winter, reflecting the greater heat stress and sweat losses (Hower et al. 1995). Horses competing in the cross-country phase of eventing exhibited increased $[\mathrm{Na}],[\mathrm{K}]$, and $\left[\mathrm{PO}_{4}\right]$ and decreased $[\mathrm{Cl}],[\mathrm{Ca}]$ and $\left[\mathrm{HCO}_{3}\right]$ resulting in a subsequent mild acidosis (Geiser et al. 1994). Cohen et al. (1993) and White et al. (1991) also observed an increase in plasma $[\mathrm{Na}]$ and a decrease in [Cl] after exercise. Conversely, Taylor et al. (1993) reported a non-significant decrease in plasma [Na], but found similarities between this study and others in changes of the concentrations of other electrolytes. However, there was no difference in plasma $[\mathrm{Na}]$ or $[\mathrm{Cl}]$ when horses underwent a much shorter duration exercise test (Hower et al. 1995) in comparison to endurance or 3-d eventing horses (Geiser et al. 1994). After racing, PCV, thiamin pyrophosphate, plasma [Na] and osmolarity of the blood were higher, while plasma [Cl] was lower than at rest (White et al. 1991).

Many trainers apparently dose their horses indiscriminately with electrolyte supplements as soon as exercise intensity or environmental temperature increases, without regard to the animals' actual requirements. Hoyt et al. (1995) determined that the amounts of electrolytes necessary to keep horses in electrolyte balance were $1.3 \mathrm{~g} \mathrm{Na}, 3 \cdot 1 \mathrm{~g} \mathrm{Cl}$ and $4.5 \mathrm{~g} \mathrm{~K} / \mathrm{Mcal}$ 
DE for horses exercising in hot, humid conditions at a level requiring $180 \%$ increase in daily DE over maintenance. An energy enriched solution of electrolytes decreased heart rate and lactate accumulation in aerobically exercised ponies (Lindner et al. 1991). Chloride concentrations are much higher in the sweat than in plasma, and losses may be as high as $110 \mathrm{mg} / \mathrm{kg}$ in horses working for $1-2 \mathrm{~h}$. The concentration of $\mathrm{Cl}$ in the sweat appears to be obligatory as there was no sparing of $\mathrm{Cl}$ losses in hypochloraemic horses (Coenen, 1991). Plasma $\mathrm{Cl}$ concentrations are dependent on intake, so that providing supplemental chloride to an animal prior to exercise may be beneficial. Coenen (1991) provided a supplement of $\mathrm{NaCl}$ in grass meal and sugar beet syrup to ponies after $1 \mathrm{~h}$ of exercise. The author concluded that providing a supplement of $\mathrm{NaCl}$ during work can increase thirst and stabilize the $\mathrm{Cl}$ concentration in the blood.

Other authors have speculated on the ability of dietary fat to alter electrolyte status in the horse. Oxidation of fat results in a lower RQ and less $\mathrm{CO}_{2}$ production than $\mathrm{CHO}$ oxidation, which may benefit the horse in maintaining $\mathrm{pH}$ homeostasis during exercise. Taylor et al. (1993) found a diet by training interaction of higher $\mathrm{P}_{\mathrm{CO}_{2}}$ and strong ion difference (SID) (calculated as the algebraic sum of the charges of the strong cations $\mathrm{Na}^{+}$ and $\mathrm{K}^{+}$and the strong anions $\mathrm{Cl}^{-}$and $\mathrm{Lac}^{-}$) after 10 weeks of conditioning in horses consuming a fat added diet. However, no decrease in $\mathrm{CO}_{2}$ production was observed in this study. Ferrante et al. (1993) found that SID decreased and $\left[\mathrm{HCO}_{3}\right]$ tended to be lower with fat supplementation in intensely exercised horses. A synergic effect between fat adaptation and $\mathrm{NaHCO}_{3}$ supplementation further increased the rise in lactate concentration and induced metabolic alkalosis above that witnessed with $\mathrm{NaHCO}_{3}$ alone. However, other studies showed no effect of fat on electrolyte balance (Hower et al. 1995; Hoyt et al. 1995).

Electrolyte status may also be manipulated by providing a ration that is either high or low in its dietary cation anion balance (DCAB). Dietary cation anion balance is calculated as mequiv. $\left(\mathrm{Na}^{+}+\mathrm{K}^{+}\right)-\mathrm{Cl}^{-} / \mathrm{kg}$ dietary dry matter (DM). Diets that have a greater portion of cations will have a higher DCAB value while those with relatively more anions will have a lower DCAB. In the GI tract, $\mathrm{H}^{+}$ions are exchanged for cations, while absorption of anions results in excretion of $\mathrm{HCO}_{3}{ }^{-}$(Stutz et al. 1992). Diets high in cations may then be able to increase the ability of the animal to guard against the decrease in $\mathrm{pH}$ accompanying lactic acid accumulation relative to diets with a more anionic nature. Resting horses consuming a highly anionic diet had lower urine $\mathrm{pH}$, blood $\mathrm{pH}, \mathrm{pCO}_{2}$ and $\left[\mathrm{HCO}_{3}\right]$ compared to animals on higher DCAB diets (Baker et al. 1993; Stutz et al. 1992; Popplewell et al. 1993). Horses consuming a highly anion diet may therefore experience metabolic acidosis. Acidosis may also result in increased excretion of Ca. Wall et al. (1992) observed a decrease of blood $\mathrm{pH}$ at rest in horses fed low DCAB diets $(5$ mequiv $/ \mathrm{kg}$ ) as well as excretion of more $\mathrm{Ca}$ and $\mathrm{Cl}$ than in horses fed diets with a DCAB of 201 or 327. Feeding high $\mathrm{CHO}$ diets was suspected to cause a decrease in $\mathrm{pH}$ and an increased urinary excretion of Ca and P (Ralston, 1994). A diet with large amounts of CHO could potentially have a low DCAB. Decreased Ca retention may result in demineralization and subsequent weakening of the skeleton after long term feeding of such diets. Diets with DCAB of greater than 200 were found to be the least acidogenic and minimized Ca and P losses (Ralston, 1994).

The effect of different $\mathrm{DCAB}$ values has been investigated in the exercising horse. Diets of $27(\mathrm{~L}), 130(\mathrm{ML}), 223(\mathrm{MH})$ and $354(\mathrm{H})$ DCAB values were fed to anaerobically trained horses. $\mathrm{H}$ diets resulted in increased $\mathrm{Na}$ and $\mathrm{Ca}$ retention. The $\mathrm{L}$ diet resulted in decreased digestibility of DM, increased faecal output, increased $\mathrm{Cl}$ retention but decreased $\mathrm{Mg}$ and $P$ retention (Wall et al. 1993). The decrease in digestion may have been related to greater acidity in the GI tract and subsequent decrease in effectiveness of enzymes. After a standard exercise test, there were no significant effects of diet on blood $\mathrm{pH}$ or on acid-base 
parameters when diets of similar DCAB values to the above study were fed (Stutz et al. 1992). Popplewell et al. (1993) reported that high DCAB diets resulted in increased blood lactate concentrations after anaerobic exercise, and heart rates were significantly lower during recovery. The authors concluded that highly cationic diets resulted in greater buffering capacity as heart rate was lower despite higher blood lactate concentrations.

\section{VITAMIN REQUIREMENTS}

Vitamins have not been studied to the extent of other nutrients, and requirements for the exercising horse are poorly defined. In spite of the lack of information, vitamin supplementation is widespread in Thoroughbred and Standardbred training barns (Gallagher et al. 1992 $a, b$ ) with little scientific evidence to support the practice. However, some interest has been devoted to this area during the last five years. A multivitamin supplement was reported to decrease $\left[\mathrm{HCO}_{3}^{-}\right]$and increase $[\mathrm{Cl}]$ before exercise as well as to decrease lactate accumulation compared with controls during a standard exercise test (McMeniman et al. 1995). Maximal heart rate was also lower in the supplemented group, but there was no effect on fitness measures including $\dot{V}_{\mathrm{O}_{2, \max }}$ or $\dot{V}_{\mathrm{La}^{4}}$. The authors indicated that the supplement may have provided one or more vitamins that were previously marginally deficient in these horses. However, it is impossible to determine, which, if any, vitamins were responsible for these effects as every vitamin but ascorbic acid and choline was added to two different diets used in this study.

Biotin has been fed to horses to aid in hoof health, but it also plays an important metabolic role in the conversion of propionate to glucose and other carboxylation reactions (Murray et al. 1993). It is also a vitamin cofactor in branched chain amino acid catabolism. It was therefore suggested that biotin supplementation could possibly enhance performance. Lindner et al. (1992) provided Thoroughbred horses in racing condition with $25 \mathrm{mg}$ biotin twice a day. Although they succeeded in increasing plasma biotin concentrations after 3 days of supplementation, there was no effect on $\mathrm{V}_{\mathrm{Ia}^{4}}$ (the speed needed to produce a lactate concentration of $4 \mathrm{mmol} / 1$ in the blood).

Vitamin E, actually a group of tocopherols and tocotrienols, has received some attention in the equine athlete. The main function of vitamin $E$ is to protect the cell against peroxidative damage (Murray et al. 1993). Therefore, lipid peroxidation as a result of exercise may be influenced by the concentration of vitamin $E$ present in the diet. Natural and synthetic sources of vitamin $E$ were equally effective in increasing serum $\alpha$-tocopherol concentrations (Gansen et al. 1995). Vitamin E supplementation increased plasma concentrations but did not change muscle concentrations or time to exhaustion (McMeniman \& Hintz, 1991). Vitamin E requirements may be less than the NRC recommendation of $80 \mathrm{IU} / \mathrm{kg} \mathrm{DM}$ as feeding exercising ponies with diets containing $42 \mathrm{IU} / \mathrm{kg}$ DM for 8 months did not decrease muscle concentrations of vitamin E, which were found to be close to saturation concentrations (McMeniman \& Hintz, 1992). Petersson et al. (1991) also stated that horses can tolerate 4 months of low vitamin $\mathrm{E}$ without clinical signs of deficiency.

\section{YEAST CULTURE AS A DIET SUPPLEMENT}

The effectiveness of yeast culture supplementation on improving performance has been studied recently. Feeding yeast is very popular, but little is known about its actual effects. It is believed to enhance the DE content of feedstuffs. Kim et al. (1991) found that feeding yeast culture (Saccharomyces cerevisiae) increased the digestibility of DM, ADF, NDF, 
hemicellulose and ash and tended to increase digestibility of CP and crude fat. Yeast supplementation also significantly increased $\mathrm{P}$ utilization $(P<0.01)$. Glade and CampbellTaylor (1990) provided yeast culture at $1 \%$ of the diet and reported an increase in hemicellulose and cellulose fermentation. In exercised horses, yeast supplementation resulted in a smaller and slower increase in lactate concentrations. Addition of yeast also increased production of volatile fatty acids (VFA) and was suggested to be similar to the effects of fat supplementation. The authors speculated that increased VFA production may enhance performance by sparing CHO. Kolterman et al. (1993) also found similarities between the effects of yeast and fat supplementation. The authors reported an interactive effect of yeast supplementation and conditioning as these horses had increased plasma triacylglycerols in addition to increased plasma glucose concentrations during the last minute of exercise and recovery compared with the non-supplemented group and data taken prior to conditioning. Glycerol concentrations were also higher during recovery. Therefore it was suggested that dietary yeast alters energy utilization during exercise and may cause a conversion of fuel usage from glycogen to fatty acids which could delay the onset of fatigue.

\section{OTHER MINERAL REQUIREMENTS}

There has been little work done in mineral metabolism beyond the initial establishment of guidelines for the macrominerals and those considered to be electrolytes. Trace mineral requirements have not been established in the working horse. Supplemental chromium was given to horses because of its role in glucose tolerance factor which potentiates the action of insulin (Pagan et al. 1995d). There was a slight effect of $\mathrm{Cr}$ on plasma glucose concentrations which were lower in the supplemented group after the 8 and $9 \mathrm{~m} / \mathrm{s}$ portions of an incremental exercise test. Cortisol concentration, which acts antagonistically to insulin, was also lower $3 \mathrm{~h}$ after feeding $(P<0.01)$ and after the warm-up trot $(P<0.05)$ (Pagan et al. 1995d).

After the onset of training, bone undergoes remodelling in response to increased stress. This process may alter requirements for minerals involved in skeletal integrity. Fifty-three yearling Quarter Horses were placed into race training, and the effects of training on bone were monitored (Nielsen et al. 1995a,b). At first the density of the third metacarpal decreased during the early stages of race training (d 0-62). After the bone density decreased, it increased most rapidly in the dorsal cortex, followed by the medial and lateral cortices (Nielsen et al. $1995 a, b$ ). Mineral requirements during this training phase and also during rapid growth of horses have not been defined clearly. Nielsen et al. (1995a) found that urinary $\mathrm{Ca}$ decreased and $\mathrm{Ca}$ retention increased during training. Calcium retention on the days when bone density was the lowest (d 28 and 56) was only 21 and $37 \%$ respectively of that on $\mathrm{d} 112$ of a training regimen Low Ca retention may have indicated a greater need for dietary $\mathrm{Ca}$ to promote higher $\mathrm{Ca}$ retention during the bone remodelling process.

Providing supplemental silicon ( $\mathrm{Si}$ ) from monosilicic acid, the bioavailable form of $\mathrm{Si}$, as sodium zeolite A (SZA), may influence changes in bone density. Silicon is present in higher concentrations in areas of the bone undergoing rapid growth than in other areas of bone (Carlisle, 1970). Feeding SZA to weanling horses resulted in an increase in plasma Si concentrations but it only minimally affected radiographic bone density (Frey et al. $1991 a, b)$. Subsequently, 53 Quarter Horses that had been given different amounts of SZA were placed into simulated race training at 18 months of age. Again, feeding SZA increased plasma Si concentrations. Horses given 1.86 and $2.8 \%$ of the diet as SZA worked greater distances than the control group before experiencing bone injuries. There was also a 
correlation between plasma Si concentrations and the distance travelled before injury in the injury-prone group (Nielsen et al. 1993). Feeding SZA did not have any detrimental effect on race performance, and Reynolds et al. (1993) reported no effect of SZA on heart rate, body temperature, $\mathrm{PCV}$, or serum concentrations of $\mathrm{Na}, \mathrm{K}, \mathrm{Ca}$, glucose, and lactate.

\section{SUMMARY}

Although a lot of research has been directed at attempts to improve performance of the equine athlete, many of the studies reviewed herein did not show statistically significant improvements in race times or increased time to fatigue. However, it must be remembered that success in racing performances is not always measured in time, but by comparative lengths or even by a nose. Therefore, improvement in the ability of an individual equine athlete is not always measurable and success is most frequently determined by one animal being better than the others in a particular competition. Therefore, any nutritional practices that have a chance to enhance an individual animal's performance, however slight, become significant when viewed in terms of the real world situation and who earns the purse at the end of the race. There have been dramatic improvements in the understanding of nutrition and metabolism in the equine athlete in recent years but numerous conflicting reports persist. It remains to be seen whether this information will result in improved performances or reduced rates of injury in the equine athletes of the world.

\section{REFERENCES}

Andrews, F. M., Ralston, S. L., Sommerdahl, C. S., Holmes, C. A., Maykuth, P. L., Green, E. M., White, S. L. \& Geiser, D. R. (1993). Weight loss, water loss, and cation balance in horses competing in 3-day event. Proceedings of the Equine Nutrition and Physiology Symposium 13, 203.

Baker, L. A., Wall, D. L., Topliff, D. R., Freeman, D. W., Teeter, R. G., Breazile, J. E. \& Wagner, D. G. (1993). Effect of dietary cation-anion balance on mineral balance in anaerobically exercised and sedentary horses. Journal of Equine Veterinary Science 13, 557-561.

Beaunoyer, D. E., Jackson, S. G., Gillespie, J. R. \& Baker, J. P. (1991). The effect of monosodium glutamate infusion on time to fatigue. Equine Exercise Physiology 3, 209-214.

Birks, E. K., Jones, J. H., Vandervort, L. J., Priest, A. K. \& Berry, J. D. (1991). Plasma lactate kinetics during exercise. Equine Exercise Physiology 3, 179-187.

Brewster-Barnes, T., Lawrence, L. M., Warren, L. K., Siciliano, P. D., Crum, A. \& Thompson, K. N. (1995). The effect of feeding after exercise on glucose and glycogen responses in the horse. Proceedings of the Equine Nutrition and Physiology Symposium 14, 50.

Carlisle, E. M. (1970). Silicon: a possible factor in bone calcification. Science 167, 279-280.

Carlson, G. P. (1995). Interrelationships between fluid, electrolyte and acid-base balance during maximal exercise. Equine Veterinary Journal, Supplement 18, 261-265.

Coenen, M. (1991). Chlorine metabolism in working horses and the improvement of chlorine supply. Proceedings of the Equine Nutrition and Physiology Symposium 12, 91.

Coenen, M., Meyer, H. \& Steinbrenner, B. (1995). Effects of $\mathrm{NaCl}$ supplementation before exercise on metabolism of water and electrolytes. Equine Veterinary Journal, Supplement 18, 270-273.

Cohen, N. D., Roussel, A. J., Lumsden, J. H., Cohen, A. C., Grift, E. \& Lewis, C. (1993). Alterations of fluid and electrolyte balance in Thoroughbred race horses following stremuous exercise during training. Canadian Journal of Veterinary Research 57, $9-13$.

Corn, C. D., Potter, G. D. \& Odom, T. W. (1991). Blood buffering in sedentary miniature horses after administration of sodium bicarbonate in single doses of varying amounts. Proceedings of the Equine Nutrition and Physiology Symposium 12, 108.

Corn, C. D., Potter, G. D. \& Odom, T. W. (1995). Blood buffering in intensely exercised miniature horses after intragastric administration of sodium bicarbonate. Proceedings of the Equine Nutrition Physiology Symposium $14,117$.

Costill, D. L. (1972). Physiology of marathon running. Journal of the American Medical Association 221, 1024-1029.

Coyne, C. P., Carlson, G. P., Spensley, M. S. \& Smith, J. (1990). Preliminary investigation of alterations in blood viscosity, cellular composition, and electrophoresis plasma protein fraction profile after competitive racing activity in thoroughbred horses. American Journal of Veterinary Research 51, 1956-1963. 
Custalow, B. (1991). Protein requirements during exercise in the horse. Journal of Equine Veterinary Science 11, 65-66.

Custalow, S. E., Ferrante, P. L., Taylor, L. E., Moll, H. D., Meacham, T. N., Kronfeld, D. S. \& Tiegs, W. (1993). Lactate and glucose responses to exercise in the horse are affected by training and dietary fat. Proceedings of the Equine Nutrition and Physiology Symposium 13, 179-184.

Danielson, K., Lawrence, L. M., Siciliano, P. D., Powell, D. \& Thompson, K. N. (1995). Effect of diet on weight and plasma variables in endurance exercised horses. Equine Veterinary Journal, Supplement 18, $372-377$.

Davie, A. J., Evans, D. L., Hodgson, D. R. \& Rose, R. J. (1994). Effects of an oral glucose polymer on muscle glycogen resynthesis in Standardbred horses. Journal of Nutrition 124, 2740s-2741s.

Davie, A. J., Evans, D. L., Hodgson, D. R. \& Rose, R. J. (1995). Effects of intravenous dextrose infusion on muscle glycogen resynthesis after intense exercise. Equine Veterinary Journal, Supplement 18, $195-198$.

Eaton, M. D., Evans, D. L., Hodgson, D. R. \& Rose, R. J. (1995a). Maximal accumulated oxygen deficit in Thoroughbred horses. Journal of Applied Physiology 78, $1564-1568$.

Eaton, M. D., Hodgson, D. R., Evans, D. L., Bryden, W. L. \& Rose, R. J. (1995b). Effect of a diet containing supplementary fat on the capacity for high intensity exercise. Equine Veterinary Journal, Supplement 18, 353-356.

Essén-Gustavsson, B., Blomstrand, E., Karlstrom, K., Lindholm, A. \& Persson, S. G. B. (1991). Influence of diet on substrate metabolism during exercise. Equine Exercise Physiology 3, 288-298.

Farris, J. W., Hinchcliff, K. W., McKeever, K. H. \& Lamb, D. R. (1995). Glucose infusion increases maximal duration of prolonged treadmill exercise in Standardbred horses. Equine Veterinary Journal, Supplement 18 , $357-361$.

Ferrante, P. L., Kronfeld, D. S., Taylor, L. E. \& Meacham, T. N. (1994a). Plasma $\left[\mathrm{H}^{+}\right]$responses to exercise in horses fed a high-fat diet and given sodium bicarbonate. Journal of Nutrition 124, (Suppl.), 2736s-2737s.

Ferrante, P. L., Menninger, J. H., Spencer, P. A. \& Kronfeld, D. S. (1992). Metabolic response of horses to a high soluble carbohydrate diet. Effects of low-intensity submaximal exercise and sodium bicarbonate supplementation. American Journal of Veterinary Research 53, 321-325.

Ferrante, P. L., Taylor, L. E., Kronfeld, D. S. \& Meacham, T. N. (1994b). Blood lactate concentration during exercise in horses fed a high-fat diet and administered sodium bicarbonate. Journal of Nutrition 124 (Suppl.), 2738 s-2739s.

Ferrante, P. L., Taylor, L. E., Meacham, T. N., Kronfeld, D. S. \& Tiegs, W. (1993). Evaluation of acid-base status and strong ion difference (SID) in exercising horses. Proceedings of the Equine Nutrition and Physiology Symposium 13, 123-124.

Foster, C. V. L. \& Harris, R. C. (1992). Total carnitine content of the middle gluteal muscle of Thoroughbred horses: normal values, variability and effect of acute exercise. Equine Veterinary Journal 24, 52-57.

Frey, K. S., Potter, G. D., Odom, T. W., Senor, D. M., Reagan, V. D., Weir, V. H., Elslander, J., Morris, E. L. \& Smith, W. B. (1991 b). Radiographic bone density in weanling Quarter Horses fed Zeolite A. Proceedings of the Equine Nutrition and Physiology Symposium 12, 23.

Frey, K. S., Potter, G. D., Odom, T. W., Senor, D. M., Reagan, V. D., Weir, V. H., Elslander, J., Webb, S. P., Morris, E. L., Smith, W. B. \& Weigland, K. E. (1991a). Plasma silicon and radiographic bone density in weanling Quarter Horses fed sodium zeolite A1. Journal of Equine Veterinary Science 12, 292-296.

Frey, L. P., Kline, K. H., Foreman, J. H., Brady, A. H. \& Cooper, S. R. (1995). Effects of warming-up, racing and sodium bicarbonate in Standardbred horses. Equine Veterinary Journal, Supplement 18, 310-313.

Gabbard, M. L., Wickler, S. J., Cogger, E. A. \& Stiffler, D. (1995). Effect of two feeds and submaximal exercise on plasma norepinephrine and epinephrine. Equine Veterinary Journal, Supplement 18, 378-381.

Gallagher, K., Leech, J. \& Stowe, H. (1992a). Protein, energy and dry matter consumption by racing Standardbreds: a field survey. Journal of Equine Veterinary Science 12, 382-388.

Gallagher, K., Leech, J. \& Stowe, H. (1992b). Protein, energy and dry matter consumption by racing Thoroughbreds: a field survey. Journal of Equine Veterinary Science 12, 43-48.

Gansen, S., Lindner, A. \& Wagener, A. (1995). Influence of a supplementation with natural and synthetic Vitamin $\mathrm{E}$ on serum $\alpha$-tocopherol content and $\mathrm{V}_{4}$ of Thoroughbred horses. Proceedings of the Equine Nutrition and Physiology Symposium 14, 68 .

Geiser, D. R., Andrews, F. M., Sommerdahl, C., White, S. L., Maykuth, P. L. \& Younger, M. S. (1994). Electrolyte and acid-base changes in combined training horses after the cross-country event. Equine Practitioner. 16 (7), 20-21, 24-25.

Glade, M. J. (1991). Timed administration of leucine, isoleucine, valine, glutamine and carnitine to enhance athletic performance. Equine Athlete 4 (5), 1, 5-10.

Glade, M. J. \& Campbell-Taylor, M. (1990). Effects of dietary yeast culture supplementation during the conditioning period on equine exercise physiology. Journal of Equine Veterinary Science 10, 434443.

Greenhaff, P. L., Hanak, J., Harris, R. C., Dobias, P., Jahn, P., Skalicky, J. \& Snow, D. H. (1991). Metabolic alkalosis and exercise performance in the Thoroughbred horse. Equine Exercise Physiology 3, 353-360.

Hanson, C. M., Kline, K. H., Foreman, J. H. \& Frey, L. P. (1993). Effect of sodium bicarbonate on plasma volume, electrolytes and blood gases in resting Quarter Horses. Proceedings of the Equine Nutrition and Physiology Symposium 13, 115-120.

Harkins, J. D. \& Kammerling, S. G. (1992). Effects of induced alkalosis on performance in Thoroughbreds during a 1600-m race. Equine Veterinary Journal 24, 9498. 
Harkins, J. D., Morris, G. S., Tulley, R. T., Nelson, A. G. \& Kammerling, S. G. (1992). Effect of added dietary fat on racing performance in Thoroughbred horses. Journal of Equine Veterinary Science 12, 123-129.

Harris, R. C., Foster, C. V. L. \& Snow, D. H. (1995). Plasma carnitine concentration and uptake into muscle following oral and intravenous administration. Equine Veterinary Journal, Supplement 18, 382-387.

Harris, R. C., Marlin, D. J. \& Snow, D. H. (1991). Lactate kinetics, plasma ammonia and performance following repeated bouts of maximal exercise. Equine Exercise Physiology 3, 173-178.

Henneke, D. R., Potter, G. D., Kreider, J. L. \& Yates, B. F. (1983). Relationship between condition score, physical measurements and body fat percentage in mares. Equine Veterinary Journal 15, 371-372.

Hinchcliff, K. W., McKeever, K. H., Muir, W. W. \& Sams, R. (1993 a). Effect of furosemide and weight carriage on energetic responses of horses to incremental exertion. American Journal of Veterinary Research 54, $1500-1504$.

Hinchcliff, K. W., McKeever, K. H., Muir, W. W. \& Sams, R. (1993b). Effect of oral sodium loading on acid: base responses of horses to intense exertion. Proceedings of the Equine Nutrition and Physiology Symposium $13,121$.

Hintz, H. F. (1994). Nutrition and equine performance. Journal of Nutrition 124 (Suppl.), 2723s-2729s.

Hodgson, D. R., Davis, R. E. \& McConaghy, F. F. (1994). Thermoregulation in the horse in response to exercise. British Veterinary Journal 150, 219-235.

Holloszy, J. O. \& Coyle, E. F. (1984). Adaptations of skeletal muscle to endurance exercise and their metabolic consequences. Journal of Applied Physiology: Respiratory, Environmental and Exercise Physiology 56, 831-838.

Hower, M. A., Potter, G. D., Greene, L. W., Coast, J. R. \& Welsh, T. H. (1995). Plasma aldosterone and electrolyte concentrations in exercising Thoroughbred horses fed two diets in summer and winter. Proceedings of the Equine Nutrition and Physiology Symposium 14, 129.

Hoyt, J. K., Potter, G. D., Greene, L. W., Vogelsang, M. M. \& Anderson, J. G. (1995). Electrolyte balance in exercising horses fed a control and fat-supplemented diet. Proceedings of the Equine Nutrition and Physiology Symposium 14, 62.

Hughes, S. J., Potter, G. D., Greene, L. W., Odom, T. W. \& Murray-Gerzik, M. (1995). Adaptation of Thoroughbred horses in training to a fat supplemented diet. Equine Veterinary Journal, Supplement 18, 349-352.

Jahn, P., Liska, I., Hanák, J., Snow, D. H., Greenhaff, P. L., Dobiás, P., Kostelecká, B. \& Skaljcky, J. (1991). Effects of exercise and metabolic alkalosis on selected plasma amino acid concentrations in Thoroughbred racehorses. Equine Exercise Physiology 3, 380-384.

Jones, D. L., Potter, G. D., Greene, L. W. \& Odom, T. W. (1991). Muscle glycogen concentrations in exercised miniature horses at various body conditions and fed a control or fat-supplemented diet. Proceedings of the Equine Nutrition and Physiology Symposium 12, 109.

Julen, T. R., Potter, G. D., Greene, L. W. \& Stott, G. G. (1995). Adaptation to a fat-supplemented diet by cutting horses. Proceedings of the Equine Nutrition and Physiology Symposium 14, 56.

Kim, S. M., Kim, C. M., Lee, H. K., Park, W. P., Lim, Y. J., Kim, B. J. \& Chung, T. Y. (1991). Evaluation of nutrient values of some feedstuffs and the effects of yeast culture supplement on digestibilities of nutrients and blood parameters in horses. Korean Journal of Animal Nutrition \& Feedstuffs 15, 272-280.

Kline, K. H., Foreman, J. H., Hanson, C. M. \& Frey, L. P. (1993). Changes in blood gases and electrolytes of horses given varying doses of sodium bicarbonate. Proceedings of the Equine Nutrition and Physiology Symposium 13, 113-114.

Kolterman, T., Miller-Graber, P. A., McCollum, D., Martinez, T. \& Sharp, R. (1993). Effects of exercise, conditioning and yeast culture supplementation on blood parameters in Quarter horses. Proceedings of the Equine Nutrition and Physiology Symposium 13, 167.

Kronfeld, D. S., Ferrante, P. L. \& Grandjean, D. (1994). Optimal nutrition for athletic performance, with emphasis on fat adaptation in dogs and horses. Journal of Nutrition 124 (Suppl.), 2745s-2753s.

Kurcz, E. V., Schurg, W. A., Marchello, J. A. \& Cuneo, S. P. (1993). The effect of exercise on plasma lipoprotein components in horses fed a high-fat diet. Proceedings of the Equine Nutrition and Physiology Symposium 13, 73.

Lawrence, L. M. (1994). Nutrition in the athletic horse. In The Athletic Horse: Principles and Practice of Equine Sports Medicine, pp. 205-230.

Lawrence, L. M., Hintz, H. F., Soderholm, L. V., Williams, J. \& Roberts, A. M. (1995). Effect of time of feeding on metabolic response to exercise. Equine Veterinary Journal, Supplement 18, 392-395.

Lawrence, L. M., Jackson, S. G., Kline, K. H., Moser, L., Powell, D. \& Biel, M. (1992). Observations on body weight and condition of horses in a 150-mile endurance ride. Journal of Equine Veterinary Science 12, 320-324.

Lawrence, L. M., Kline, K. H., Miller-Graber, P. A., Siegel, A., Kurcz, E. V., Fisher, M. G. \& Bump, K. D. (1990). Effect of sodium bicarbonate on racing Standardbreds. Journal of Animal Science 68, 673-677.

Lawrence, L. M., Soderholm, L. V., Roberts, A. M., Williams, J. \& Hintz, H. F. (1993). Feeding status affects glucose metabolism in exercising horses. Journal of Nutrition 123, 2152-2157.

Lindner, A., Witte, P. V., Bendig, M. \& Sommer, H. (1991). Effect of an energy enriched electrolyte fluid concentration on heart rate and lactate concentration of ponies during and after exercise. Proceedings of the Equine Nutrition and Physiology Symposium 12, 93.

Lindner, A., von Wittke, P. \& Frigg, M. (1992). Effect of biotin supplementation on the VL $_{A 4}$ of Thoroughbred horses. Journal of Equine Veterinary Science 12, 149-151.

Lloyd, D. R., Evans, D. L., Hodgson, D. R., Suann, C. J. \& Rose, R. J. (1993). Effects of sodium bicarbonate on cardiorespiratory measurements and exercise capacity. Equine Veterinary Journal 25, 125-129. 
Lloyd, D. R. \& Rose, R. J. (1995). Effects of sodium bicarbonate on acid-base status and exercise capacity. Equine Veterinary Journal, Supplement 18, 323-325.

McMeniman, N. P. \& Hintz, H. F. (1992). Effect of vitamin E status on lipid peroxidation in exercised horses. Equine Veterinary Journal 24, 482-484.

McMeniman, N. P., Thornton, J. R. \& Dowsett, K. F. (1995). Effect of grain type and vitamin supplementation on performance of exercising horse. Equine Veferinary Journal, Supplement 18, 367-371.

Meyer, H. (1995). Influence of diet, exercise and water restrictions on the gut fill in horses. Proceedings of the Equine Nutrition and Physiology Symposium 14, 90.

Miller-Graber, P. A., Lawrence, L. M., Foreman, J. H., Bump, K. D., Fisher, M. G. \& Kurcz, E. V. (1991a). Metabolic responses to ammonium acetate infusion in exercising horses. Cornell Veterinarian 81, 397-410.

Miller-Graber, P. A., Lawrence, L. M., Foreman, J. H., Bump, K. D., Fisher, M. G. \& Kurcz, E. V. (1991b). Effect of dietary protein level on nitrogen metabolites in exercised Quarter Horses. Equine Exercise Physiology 3, 305-314.

Miller-Graber, P. A., Lawrence, L. M., Foreman, J. H., Bump, K. D., Fisher, M. G. \& Kurcz, E. V. (1991c). Dietary protein level and energy metabolism during treadmill exercise in horses. Journal of Nutrition 121, $1462-1469$

Miller-Graber, P. A., Lawrence, L. M., Kurcz, E. V., Kane, R., Bump, K. D., Fisher, M. G. \& Smith, J. (1990). The free amino acid profile in the middle gluteal muscle before and after fatiguing exercise in the horse. Equine Veterinary Journal 22, 209-210.

Miller-Graber, P. A. \& Syers, M. (1993). Effect of dietary histidine level on selected blood and muscle amino acids and metabolites in the mature horse. Proceedings of the Equine Nutrition and Physiology Symposium 13, 56-57.

Morgan, E. K. M. (1995). Climatic energy demand of horses. Equine Veterinary Journal, Supplement 18, $396-399$.

Moser, L., Lawrence, L. M., Novakofski, J., Powell, D. \& Biel, M. (1991). The effect of supplemental fat on exercising horses. Proceedings of the Equine Nutrition and Physiology Symposium 12, 103.

Mueller, P. J., Rawson, R. E., Van Soest, P. J. \& Hintz, H. F. (1995). Influence of nutritional status on metabolic responses to exercise in donkeys. Equine Veterinary Journal, Supplement 18, 400-405.

Murray, R. K., Granner, D. K., Mayes, P. A. \& Rodwell, V. W. (1993), Harper's Biochemistry, 23 rd edn. Connecticut: Appleton and Lange.

National Research Council. (1989). Nutrient Requirements of Horses, 5th rev. edn. Washington D.C.: National Academy Press.

Naylor, J. R. J., Bayly, W. M., Schott, H. C., Gollnick, P. D. \& Hodgson, D. R. (1993). Equine plasma and blood volumes decrease with dehydration but subsequently increase with exercise. Journal of Applied Physiology $\mathbf{7 5}$, $1002-1008$.

Nielsen, B. D., Potter, G. D., Greene, L. W., Morris, E. L., Murray-Gerzik, M., Smith, W. B. \& Martin, M. T. (1995a). Does the onset of training alter the mineral requirements in the young racing Quarter Horse? Proceedings of the Equine Nutrition and Physiology Symposium 14, 70.

Nielsen, B. D., Potter, G. D., Morris, E. L., Odom, T. W., Senor, D. M., Reynolds, J. A., Smith, W. B. \& Martin, M. T. $(1995 \mathrm{~b})$. Modifications of the third metacarpal bone in young racing Quarter Horses as a result of training. Proceedings of the Equine Nutrition and Physiology Symposium 14, 102-107.

Nielsen, B. D., Potter, G. D., Morris, E. L., Odom, T. W., Senor, D. M., Reynolds, J. A., Smith, W. B., Martin, M. T. \& Bird, E. H. (1993). Training distance to failure in young racing Quarter Horses fed sodium Zeolite A. Proceedings of the Equine Nutrition and Physiology Symposium 13, 5.

Oldham, S. L., Potter, G. D., Evans, J. W., Smith, S. B., Taylor, T. S. \& Barnes, W. S. (1990). Storage and mobilization of muscle glycogen in exercising horses fed a fat-supplemented diet. Journal of Equine Veterinary Science 10, 353-355, 358-359.

Orme, C. E., Harris, R. C. \& Marlin, D. J. (1995). Effect of elevated plasma FFA on fat utilisation during low intensity exercise. Equine Veterinary Journal Supplement 18, 199-204.

Pagan, J. D., Burger, I. \& Jackson, S. G. (1995a). The long term effects of feeding fat to 2-year-old Thoroughbreds in training. Equine Veterinary Journal, Supplement 18, 343-348.

Pagan, J. D., Burger, I. \& Jackson, S. G. (1995b). The influence of time of feeding on exercise response in Thoroughbreds fed a fat supplemented or high carbohydrate diet. Proceedings of the Equine Nutrition and Physiology Symposium 14, 92.

Pagan, J. D., Essén-Gustavsson, B., Lindholm, A. \& Thornton, J. R. (1987). The effect of dietary energy source on exercise performance in Standardbred Horses. Equine Exercise Physiology 2, 686-700.

Pagan, J. D., Rotmensen, T. \& Jackson, S. G. (1995c). Responses of blood glucose, lactate and insulin in horses fed equal amounts of grain with or without added soybean oil. Proceedings of the Equine Nutrition and Physiology Symposium 14, 13.

Pagan, J. D., Rotmensen, T. \& Jackson, S. G. (1995d). The effect of chromium supplementation on metabolic response to exercise in Thoroughbred horses. Proceedings of the Equine Nutrition and Physiology Symposium 14, 96.

Pagan, J. D., Tiegs, W., Jackson, S. G. \& Murphy, H. Q. (1993). The effect of different fat sources on exercise performance in Thoroughbred racing horses. Proceedings of the Equine Nutrition and Physiology Symposium 13, $125-129$.

Pendergraft, J. \& Arns, M. J. (1993). Tall fescue utilization in exercised yearling horses. Proceedings of the Equine Nutrition and Physiology Symposium 13, 106. 
Petersson, K. H., Hintz, H. F., Schryver, H. F. \& Combs, G. F. Jr, (1991). The effect of vitamin E on membrane integrity during submaximal exercise. Equine Exercise Physiology 3, 315-322.

Pethick, D. W., Rose, R. J., Bryden, W. L. \& Gooden, J. M. (1993). Nutrient utilisation by the hindlimb of Thoroughbred horses at rest. Equine Veterinary Journal 25, 41-44.

Popplewell, J. C., Topliff, D. R., Freeman, D. W. \& Breazile, J. E. (1993). Effects of dietary cation-anion balance on acid base balance and blood parameters in anaerobically exercised horses. Proceedings of the Equine Nutrition and Physiology Symposium 13, 191-196.

Potter, G. D., Webb, S. P., Evans, J. W. \& Webb, G. W. (1990). Digestible energy requirements for work and maintenance of horses fed conventional and fat-supplemented diets. Journal of Equine Veterinary Science 10 , 214-218.

Powell, D., Lawrence, L. M., Novakofski, J., Moser, L. \& Biel, M. (1991). Effect of dietary L-histidine supplementation on muscle carnosine and buffering capacity in horses. Proceedings of the Equine Nutrition and Physiology Symposium 12, 115.

Powers, S. K. \& Howley, E. T. (1994). Exercise Physiology: Theory and Application to Fitness and Performance, 2nd edn. Wisconsin: Brown \& Benchmark.

Pösö, A. R., Essén-Gustavsson, B., Lindholm, A. \& Persson, S. G. B. (1991). Exercise-induced changes in muscle and plasma amino acid levels in the Standardbred horse. Equine Exercise Physiology 3, 202-208.

Ralston, S. L. (1994). The effect of diet on acid-base status and mineral excretion in horses. Equine Practitioner $16(7), 10-13$

Reynolds, J. A., Potter, G. D., Odom, T. W., Vogelsang, M. M., Smith, W. B., Nielsen, B. D., Senor, D. M. \& Bird, E. H. (1993). Physiological responses to training in racing two-year old Quarter horses fed sodium Zeolite A. Proceedings of the Equine Nutrition and Physiology Symposium 13, 197.

Rich, G. A., Fontenot, J. P.\& Meacham, T. N. (1981). Digestibility of animal, vegetable, and blended fats by the equine. Proceedings of the Equine Nutrition and Physiology Symposium 7, 30.

Roberts, A. M., Lawrence, L. M., Schryver, H. F., Williams, J., Soderholm, L. V. \& Hintz, H. F. (1991). Metabolic changes in exercised horses given sodium bicarbonate. Proceedings of the Equine Nutrition and Physiology Symposium 12, 159.

Rodiek, A. V., Bonvicin, S., Stull, C. L. \& Arana, M. (1991). Glycemic and endocrine responses to corn or alfalfa fed prior to exercise. Equine Exercise Physiology 3, 323-330.

Rose, R. J., Knight, P. K. \& Bryden, W. L. (1991). Energy use and cardiorespiratory responses to prolonged submaximal exercise. Equine Exercise Physiology 3, 281-287.

Schott, H. C. \& Hinchcliff, K. W. (1993). Fluids, electrolytes, and bicarbonate. Veterinary Clinics of North America, Equine Practice 9, 577-604.

Scott, B. D., Potter, G. D., Greene, L. W., Hargis, P. S. \& Anderson, J. G. (1992). Efficacy of a fat-supplemented diet on muscle glycogen concentrations in exercising Thoroughbred horses maintained in varying body conditions. Journal of Equine Veterinary Science 12, 109-113.

Scott, B. D., Potter, G. D., Greene, L. W., Vogelsang, M. M. \& Anderson, J. G. (1993). Efficacy of a fatsupplemented diet to reduce thermal stress in exercising Thoroughbred horses. Proceedings of the Equine Nutrition and Physiology Symposium 13, 66-71.

Sewell, D. A. \& Harris, R. C. (1995). Effects of creatine supplementation in the Thoroughbred horse. Equine Veterinary Journal, Supplement 18, 239-242.

Sewell, D. A., Harris, R. C., Marlin, D. J. \& Dunnett, M. (1992). Estimation of the carnosine content of different fibre types in the middle gluteal muscle of the thoroughbred horse. Journal of Physiology 455, 447-453.

Snow, D. H. \& Harris, R. C. (1991). Effects of daily exercise on muscle glycogen in the Thoroughbred racehorse. Equine Exercise Physiology 3, 299-304.

Sommerdahl, C. S., Andrews, F. M., Saxton, A. M., Geiser, D. R. \& Maykuth, P. L. (1994). Alterations in blood viscosity in horses competing in cross country jumping. American Journal of Veterinary Research 55, 389-394.

Southwood, L. L., Evans, D. L., Hodgson, D. R., Bryden, W. L. \& Rose, R. J. (1993). The effect of roughage source on exercise performance and metabolism in thoroughbred horses. Cornell Veterinarian 83, 243-255.

Sticker, L. S., Thompson, D. L., Fernandez, J. M., Fischer, S. P. \& Nadal, M. R. (1995). Feed deprivation in mares: characterization of plasma metabolic and hormonal concentrations and responses to exercise. Proceedings of the Equine Nutrition and Physiology Symposium 14, 23.

Stull, C. L. \& Rodiek, A. V. (1995a). Effects of postprandial interval and feed components on stress parameters in exercising Thoroughbreds. Proceedings of the Equine Nutrition and Physiology Symposium 14, 17.

Stull, C. L. \& Rodiek, A. V. (1995 b). Effects of post prandial interval and feed type on substrate availability during exercise. Equine Veterinary Journal, Supplement 18, 362-366.

Stutz, W. A., Topliff, D. R., Freeman, D. W., Tucker, W. B., Breazile, J. W. \& Wall, D. L. (1992). Effect of dietary cation-anion balance on blood parameters in exercising horses. Journal of Equine Veterinary Science 12, $164-167$.

Sweeney, D. L., Potter, G. D., Greene, L. W., Schumacher, J., Murray-Gerzik, M. \& Goldy, G. (1995). Digestion of fat in the equine small and large intestine. Proceedings of the Equine Nutrition and Physiology Symposium 14, $30-35$.

Taylor, L. E., Ferrante, P. L., Meacham, T. N., Kronfeld, D. S. \& Tiegs, W. (1993). Acid-base responses to 
exercise in horses trained on a diet containing added fat. Proceedings of the Equine Nutrition and Physiology Symposium 13, 185-189.

Taylor, L. E., Ferrante, P. L., Wilson, J. A. \& Kronfeld, D. S. (1995). Acid-base status and blood variables during repeated sprint exercise in horses fed lecithin. Proceedings of the Equine Nutrition and Physiology Symposium 14, 94.

Wall, D. L., Topliff, D. R., Freeman, D. W., Breazile, J. W. \& Wagner, D. G. (1991). Effect of dietary cationanion balance on mineral metabolism in exercised horses. Proceedings of the Equine Nutrition and Physiology Symposium 12, 121-126.

Wall, D. L., Topliff, D. R., Freeman, D. W., Wagner, D. G., Breazile, J. W. \& Stutz, W. A. (1992). Effect of dietary cation-anion balance on urinary mineral excretion in exercised horses. Journal of Equine Veterinary Science 12, 168-171.

Warren, L. K., Thompson, K. N., Lawrence, L. M. \& Brewster-Barnes, T. (1995). The influence of trimethylglycine in the trained untrained horse exercising to fatigue. Proceedings of the Equine Nutrition and Physiology Symposium 14, 123.

Webb, S. P., Potter, G. D., Evans, J. W. \& Webb, G. W. (1990). Influence of body fat content on digestible requirements of exercising horses in temperate and hot environments. Journal of Equine Veterinary Science 10 , $116-120$.

White, A., Reyes, A., Godoy, A. \& Martinez, R. (1991), Effects of transport and racing on ionic changes in thoroughbred race horses. Comparative Biochemistry and Physiology A 99, 343-346.

Wickler, S. J., Pauley, P. S., Bray, R. E., London, C. \& Gabbard, M. L. (1995). Performance at high altitude of horses and mules receiving fat supplemented diets. Equine Veterinary Joumal, Supplement 18, $406-409$.

Wilson, J. A., Williams, J., Kronfeld, D. S., Gay, L. \& Wilson, T. (1995). Sarcoplasmic reticulum responses to dietary lecithin. Proceedings of the Equine Nutrition and Physiology Symposium 14, 15.

Younglove, G. A., Gibbs, P. G., Potter, G. D., Murray-Gerzik, M. \& Dorsett, D. J. (1994). Comparative feeding value of cubed alfalfa : corn plant product as an exclusive diet for exercising horses. Journal of Equine Veterinary Science 14, 598-602.

Zimmerman, N. I., Wickler, S. J., Rodiek, A. V. \& Hower, M. A. (1992). Free fatty acids in exercising Arabian horses fed two common diets. Journal of Nutrition 122, 145-150. 